\title{
Catalogue of Large Magellanic Cloud star clusters observed in the Washington photometric system
}

\author{
T. Palma ${ }^{1,2,3}$, L. V. Gramajo ${ }^{3}$, J. J. Clariá3,4, M. Lares ${ }^{3,4,5}$, D. Geisler ${ }^{6}$, and A. V. Ahumada ${ }^{3,4}$ \\ 1 Millennium Institute of Astrophysics, Nuncio Monseñor Sotero Sanz 100, Providencia, Santiago, Chile \\ e-mail: tpalma@astro.puc.cl \\ 2 Instituto de Astrofísica, Pontificia Universidad Católica de Chile, Av. Vicuña Mackenna 4860, $782-0436$ Macul, Santiago, Chile \\ 3 Observatorio Astronómico, Universidad Nacional de Córdoba, Laprida 854, 5000 Córdoba, Argentina \\ ${ }^{4}$ Consejo Nacional de Investigaciones Científicas y Técnicas (CONICET), Argentina \\ 5 Instituto de Astronomía Teórica y Experimental (IATE), 922 Laprida, Córdoba, Argentina \\ ${ }^{6}$ Departamento de Astronomía, Universidad de Concepción, Casilla 160-C, Concepción, Chile
}

Received 4 September 2015/Accepted 17 November 2015

\section{ABSTRACT}

\begin{abstract}
Aims. The main goal of this study is to compile a catalogue of the fundamental parameters of a complete sample of 277 star clusters (SCs) of the Large Magellanic Cloud (LMC) observed in the Washington photometric system. A set of 82 clusters was recently studied by our team.

Methods. All the clusters' parameters such as radii, deprojected distances, reddenings, ages, and metallicities were obtained by applying essentially the same procedures, which are briefly described here. We used empirical cumulative distribution functions to examine age, metallicity and deprojected distance distributions for different cluster subsamples of the catalogue.

Results. Our new sample of 82 additional clusters represents about a $40 \%$ increase in the total number of LMC SCs observed to date in the Washington photometric system. In particular, we report here the fundamental parameters obtained for the first time for 42 of these clusters. We found that single LMC SCs are typically older than multiple SCs. Both single and multiple SCs exhibit asymmetrical distributions in log (age). We compared cluster ages derived through isochrone fittings obtained using different models of the Padova group. Although ages obtained using recent isochrones are consistent in general terms, we found that there is some disagreement in the obtained values and their uncertainties.
\end{abstract}

Key words. techniques: photometric - Magellanic Clouds - galaxies: star clusters: general

\section{Introduction}

The Magellanic Clouds have long been considered an ideal laboratory to study a variety of objects and phenomena in nearby galaxies. In particular, the Large Magellanic Cloud (LMC) has been a target of intensive research because of its proximity and its almost face-on position in the sky (Harris \& Zaritsky 2009), which facilitates a detailed analysis of its stellar populations. Various studies of LMC star clusters (SCs) have shown that these stellar populations differ from Galactic SCs in their typical radii, masses, kinematics, age distribution, etc. The nature and cause of the so-called cluster age-gap of approximately 3 to $12 \mathrm{Gyr}-$ only a single cluster is found in this range in the LMC (Geisler et al. 1997) - is of great interest, even more so considering that a variety of HST observations have revealed that the corresponding age-gap in the field stars does not exist (e.g., Holtzman et al. 1999; Smecker-Hane et al. 2002). Unfortunately, this vast cluster age-gap does not allow us to use SCs to trace the chemical enrichment and star-formation history of the LMC during such a long period of quiescence. However, the great abundance of clusters outside of this gap make them excellent tracers of these quantities otherwise.

The Washington photometric system, originally defined to study $\mathrm{G}$ and $\mathrm{K}$ late-type stars and old stellar populations (Canterna 1976) and later calibrated by Geisler et al. (1991), has been widely applied to young, intermediate-age and old clusters in the Galaxy (e.g., Clariá et al. 2007; Piatti et al. 2009a) and in the Magellanic Clouds (e.g. Geisler et al. 2003). This system has proved to be an excellent tool to determine a variety of astrophysical parameters such as distances, interstellar absorption, ages and particularly chemical abundances (metallicities) for SCs as well as for field stars located in the cluster surrounding regions. The advantages that this system offers to study Galactic and/or extragalactic SCs have been demonstrated by Geisler et al. (1991, 1997) and Geisler \& Sarajedini (1999). In particular, the combination of the Washington system $C$ and $T_{1}$ filters is approximately three times more metallicitysensitive than the corresponding VI standard giant branch technique. This, combined with the Washington system's broad and efficient passbands, makes it a very powerful tool for exploring stellar populations in both nearby and especially more distant galaxies. In addition, Geisler (1987) has shown that the system can be made even more efficient by substituting the KronCousins $R$ filter for the standard Washington $T_{1}$ filter. In fact, the $R$ filter has a very similar wavelength coverage but a significantly higher throughput as compared to the standard Washington $T_{1}$ filter. Therefore, $R$ instrumental magnitudes can be easily and accurately transformed to yield standard $T_{1}$ magnitudes. As shown by Geisler \& Sarajedini (1999), the combined use of the $C$ and $R$ filters allows us to derive accurate metallicities based on their standard giant branch (SGB) technique. Using LMC SCs observed in the Washington photometric system, we have recently examined the chemical enrichment history of the LMC during the last 2-3 Gyr (Palma et al. 2015).

The fundamental parameters of a total of 195 LMC SCs have been determined using the Washington system in a number of 
papers over the years. A short description of the selected sample criteria is summarized in Table 1 . We have recently published the results obtained for 40 unstudied or poorly studied SCs (Palma et al. 2013, 2015). In the current study, we report the results obtained for another 42 LMC SCs, all of them observed in the Washington system. Thus, this combined sample of 82 clusters represents about a $40 \%$ increase in the total of LMC clusters observed and studied up to this moment in the Washington photometric system. Since all the clusters' parameters were obtained by applying essentially the same procedures, this group of objects represents a uniform and homogeneous cluster sample. Although the total sample still represents only a tiny fraction of the very populous LMC SC system, it is in fact one of the largest and most uniform LMC SC samples available and thus a catalogue uniting the combined information in a single dataset should be of substantial general astrophysical use.

\section{Observations}

We have compiled a catalogue including a total of 277 LMC SCs studied in the Washington system. All the photometric observations of these SCs were carried out at Cerro Tololo InterAmerican Observatory (CTIO, Chile), using the Wahington $C$ and $T_{1}$ filters (Canterna 1976) and the Kron-Cousins $R$ filter. As mentioned in Palma et al. (2015), our new sample of 82 SCs was observed with the CTIO "Víctor Blanco" $4 \mathrm{~m}$ telescope in December 2000. The CTIO $0.9 \mathrm{~m}$ telescope was used by Geisler et al. (1997, 2003), Bica et al. (1998), and Piatti et al. (2002, 2003a,b, 2009b, 2011), while the observations reported by Geisler (1987), Piatti (2011, 2012), Palma et al. (2013, 2015), and Choudhury et al. (2015) were also carried out with the CTIO $4 \mathrm{~m}$ telescope. Only one LMC cluster (NGC 2213) was observed with the CTIO $1.5 \mathrm{~m}$ telescope. The seeing at CTIO was typically $1-1.5$ arcsec during all the observing nights.

The total cluster sample is presented in Table A.1, where we list the various star cluster designations from different catalogues, 2000.0 equatorial coordinates, Galactic coordinates, and the cluster core radii given by Bica et al. (2008). These core radii constitute half of the mean apparent central diameters obtained by computing the average between the major (a) and minor (b) axes. Figure 1 shows a distribution map of the whole sample of LMC clusters studied in the Washington photometric system superimposed on the LMC image. The dashed lines delimit the LMC bar region. Filled circles represent the 82 clusters of our recent sample, while plus signs stand for clusters studied by other authors using the same technique and analysis procedures.

\section{Fundamental parameters}

The procedures that we applied to determine the LMC SCs fundamental parameters in the Washington system have also been used by other authors and are briefly described below. For further details see Palma et al. (2013) and references therein.

Cluster radii: the procedure generally applied to determine a cluster's radius is based on obtaining the radial profile of the stellar density surrounding the cluster. Firstly, it is necessary to determine the cluster centre through Gaussian distribution fits to the star counts performed in the $\mathrm{x}$ and $\mathrm{y}$ directions. The most important sources of uncertainty in the placement of cluster centres come from the relatively small ratio between the number of cluster and field stars, and the projected intracluster fluctuations due to both cluster and field star density variations. Then, the cluster radial profile is built by computing the number of stars per unit area at a given radius $r$. Once the level of the background is estimated beyond the observed cluster boundary, the radius of the

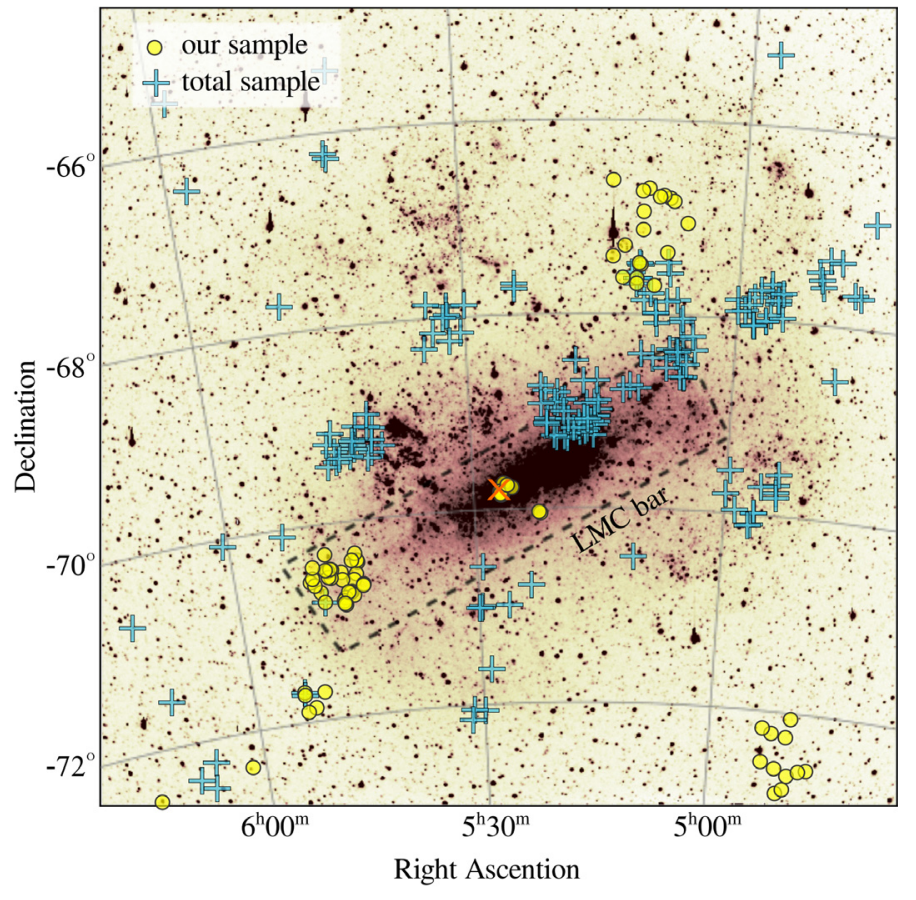

Fig. 1. Distribution map of the whole sample of star clusters studied in the Washington photometric system superimposed on the LMC galaxy image. Filled circles represent the clusters of our own sample, while plus signs stand for clusters studied by other authors using the same technique and analysis procedures. The cross indicates the geometrical centre of the bar (Bok 1966). The credits for the background image belongs to Bothun \& Thompson (1988), Kennicutt et al. (1995) and Parker et al. (1998).

cluster is defined as the distance from the cluster's centre where the number of stars per unit area (cluster+background) equals that of the estimated background level. Error estimates for the radii range typically between $0.05^{\prime}$ and $0.2^{\prime}$ depending on the telescope used, the concentration of the cluster, and the position within the LMC. Examples of the procedure described here to determine cluster radii can be seen in Palma et al. (2013). In a few cases, when the clusters appear to be too faint compared to the "noisy" background, the core radii reported by Bica et al. (2008) were adopted.

Angular deprojected distances: the angular deprojected distance of a LMC cluster is the distance, measured in degrees, from the optical centre of the LMC to the cluster, taking into account the depth of the LMC and is computed using the expression (Clariá et al. 2005)

$d=d(p)\left\{1+\left[\sin \left(p-p^{\prime}\right)^{2}\right]\left[\tan (i)^{2}\right]\right\}^{0.5}$,

where $d$ is the cluster angular deprojected distance, $d(p)$ the angular projected distance on the plane of the sky, $p$ the position angle of the cluster (measured in the usual sense towards E starting from $\mathrm{N}$ ), $p^{\prime}$ the position angle of the line of nodes and $i$ the tilt of the LMC plane to the plane of the sky. The position of the cluster NGC $1928\left(\mathrm{~J} 2000, \alpha=5^{\mathrm{h}} 20^{\mathrm{m}} 47^{\mathrm{s}} \delta=-69^{\circ} 28^{\prime} 41^{\prime \prime}\right)$ was adopted as the LMC optical centre. To compute $d$ from Eq. (1), we adopted $i=35.8^{\circ} \pm 2.4^{\circ}$ and $p^{\prime}=145^{\circ} \pm 4^{\circ}$ for the tilt of the LMC plane and the position angle of the line of nodes, respectively (Olsen \& Salyk 2002). We carried out an error analysis in order to measure the uncertainties involved in the geometric parameters. We found that our estimated error in deriving this quantity increases with the angular projected distance and reaches a maximum value of $\sim 0.3^{\circ}$. 
T. Palma et al.: Catalogue of LMC star clusters observed in the Washington system.

Table 1. Description of selected LMC SC samples found in the literature.

\begin{tabular}{lclc}
\hline \hline Authors & Selected SCs & Characteristics/selection criteria & CTIO telescope \\
\hline Geisler (1987) & 1 & Technique tests & $1.5 \mathrm{~m}$ \\
Geisler et al. (1997) & 25 & Search for old SC candidates & $0.9 \mathrm{~m}$ \\
Bica et al. (1998) & 13 & SC properties in the outer LMC & $0.9 \mathrm{~m}$ \\
Piatti et al. (2002) & 2 & Cluster age gap and first metallicity determination & $0.9 \mathrm{~m}$ \\
Geisler et al. (2003) & 8 & Metallicity determinations for some SCs from Geisler et al. (1997) & $0.9 \mathrm{~m}$ \\
Piatti et al. (2003b) & 11 & Blue SCs in the west region of the LMC bar & $0.9 \mathrm{~m}$ \\
Piatti et al. (2003a) & 6 & Systematic study & $0.9 \mathrm{~m}$ \\
Piatti et al. (2009b) & 5 & Systematic study; mostly unstudied clusters & $0.9 \mathrm{~m}$ \\
Piatti (2011) & 36 & Bursting forming episode & $4 \mathrm{~m}$ \\
Palma et al. (2011) & 4 & Systematic study; unstudied clusters & $4 \mathrm{~m}$ \\
Piatti (2012) & 26 & Enlarging the sample of SCs in the 100-1000 Myr age range & $4 \mathrm{~m}$ \\
Palma et al. (2013) & 23 & Systematic study; mostly unstudied clusters; age/metallicity gradients & $4 \mathrm{~m}$ \\
Piatti (2014) & 90 & Search for genuine SCs and age determinations & $4 \mathrm{~m}$ \\
Palma et al. (2015) & 17 & Systematic study; mostly unstudied clusters; age-metallicity relation & $4 \mathrm{~m}$ \\
Choudhury et al. (2015) & 45 & Search for genuine SCs and characterization & $4 \mathrm{~m}$ \\
\hline
\end{tabular}

Interstellar reddening and cluster distances: clusterreddening values are usually estimated by interpolating the extinction maps of Burstein \& Heiles (1982). These maps were obtained from HI $(21 \mathrm{~cm})$ emission data for the southern sky and provided us with foreground $E(B-V)$ colour excesses, which depend on the Galactic coordinates. As shown in Col. 4 of Table A.1, the resulting $E(B-V)$ values for the whole cluster sample range between 0.00 and 0.23 , which are typical values for the LMC. As explained in previous studies, we preferred not to use the full-sky maps from $100 \mu$ dust emission obtained by Schlegel et al. (1998) since the dust temperature and reddening derived from pointing towards the LMC and other bright extragalactic sources are not reliable in these cases (e.g. Piatti et al. 2011). For the cluster distance moduli, the value of the LMC true distance modulus $(m-M)_{0}=18.50 \pm 0.10$ reported by Saha et al. (2010) has always been adopted. According to Subramanian \& Subramaniam (2009), the average depth for the LMC disc is $3.44 \pm 0.16 \mathrm{kpc}$. Keeping in mind that any LMC cluster could be situated in front of or behind the main body of the LMC, we come to the conclusion that the difference in apparent distance modulus could be as large as $\Delta\left(V-M_{V}\right) \sim$ $0.3 \mathrm{mag}$. Given that the average uncertainty when adjusting the isochrones to the cluster colour-magnitude diagrams (CMDs) is 0.2-0.3 mag, adopting one single value for the distance modulus of all the clusters should not dominate the error budget in the final results.

Ages and metallicities: cluster ages and metallicities are usually determined by applying two different and independent procedures. In both cases, however, it is necessary to first obtain the observed cluster $\left(C-T_{1}, T_{1}\right) \mathrm{CMD}$ and then to minimize the field star contamination in this diagram. The CMDs of the 82 clusters of our recent sample were cleaned by using a statistical method developted by Piatti \& Bica (2012). Once the cleaned CMDs of the clusters are obtained, the first method consists in selecting a set of theoretical isochrones corresponding to different ages and metallicities and superimposing them on the cleaned cluster CMDs once they are properly shifted by the corresponding $E(B-V)$ colour excess and LMC distance modulus. The age and metallicity adopted for each cluster are those corresponding to the isochrone which best matches the shape and position of the cluster main sequence (MS), particularly at the turn-off (TO) level, as well as the $T_{1}$ magnitude of the red giant clump (RGC). To apply this method, theoretical isochrones computed for the Washington system by the Padova group (Girardi et al. 2002; Bressan et al. 2012) and Geneva group (Lejeune \& Schaerer 2001) were used. Lejeune \& Schaerer (2001) and Girardi et al. (2002) isochrones were computed for chemical compositions of $Z=0.019,0.008$, and 0.004 , equivalent to $[\mathrm{Fe} / \mathrm{H}]=0.0,-0.4$, and -0.7 , while the more recent Bressan et al. (2012) models include isochrones having metallicities between $[\mathrm{Fe} / \mathrm{H}]=-0.19$ and -0.84 , which vary in an almost continuous way. For 23 out of the 82 clusters of our sample reported in Palma et al. (2013) we initially used Girardi et al. (2002) isochrones; however, for the present analysis we used Bressan et al. (2012) isochrones for the entire sample because they include much smaller intervals in chemical composition $(Z)$ than those used by Girardi et al. (2002). Thus, more precise fits could then be obtained. In general, the different sets of theoretical isochrones both from Padova and Geneva lead to nearly similar results. The differences arising when different sets of isochrones of the Padova group are used can be seen in Fig. 5.

A second method used to derive cluster ages is based on the $\delta T_{1}$ parameter, defined as the difference in $T_{1}$ magnitude between the RGC and the MSTO in the Washington $\left(C-T_{1}, T_{1}\right)$ $\mathrm{CMD}$. The age is obtained from the equation given in Geisler et al. (1997)

$$
\operatorname{Age}(\mathrm{Gyr})=0.23+2.31 \times \delta T_{1}-1.80 \times \delta T_{1}^{2}+0.645 \times \delta T_{1}^{3},
$$

with a typical error of \pm 0.3 Gyr. Age determination via $\delta T_{1}$; however, it is applicable only to intermediate-age clusters (IACs) and/or old clusters, i.e. generally older than 1 Gyr. Even though some clusters appeared to be IACs (1-3 Gyr), it was not possible to determine their ages from $\delta T_{1}$ because the RGC in their CMDs was not clearly visible. This happened because sometimes the central regions of the clusters were saturated, or there were only a very few RC stars in some faint clusters, or else they were not photometrically well resolved in the images. In these cases, the RG stars are missing or poorly defined and therefore no clump can be clearly detected in the CMDs. The resulting $\delta T_{1}$ values and the corresponding cluster ages are listed in Col. 7 of Table A.2.

Metallicities have also been obtained utilizing the SGBs of Geisler \& Sarajedini (1999) by placing the observations in the $\left[M_{T_{1}},\left(C-T_{1}\right)_{0}\right]$ plane utilizing the equations $E\left(C-T_{1}\right)=$ $1.97 E(B-V)$ and $M_{T_{1}}=T_{1}+0.58 E(B-V)-\left(V-M_{V}\right)$. Each SGB corresponds to an iso-abundance curve. These authors suggest, however, that this procedure can be applied only 
to SCs aged 2 Gyr or older. Geisler \& Sarajedini (1999) demonstrated that the metallicity sensitivity of the SGBs is three times higher than that of the V, I technique (Da Costa \& Armandroff 1990). Consequently, it is feasible to determine metallicities three times more precisely for a given photometric error. The SGB method consists of inserting absolute $M_{T_{1}}$ magnitudes and intrinsic $\left(C-T_{1}\right)_{0}$ colours for the clusters into Fig. 4 of Geisler $\&$ Sarajedini (1999) to roughly derive their metal abundances $([\mathrm{Fe} / \mathrm{H}])$ by interpolation. The metallicities derived through this method were corrected for age effects for younger clusters, following the recommendations made by Geisler et al. (2003). The resulting age corrected metallicities are shown in Col. 8 of Table A.2, with typical errors of 0.3 dex.

\section{Catalogue description}

We have compiled a catalogue in which we included the fundamental parameters of 277 LMC SCs observed in the Washington photometric system. All these clusters have been studied and analysed in a homogeneous way. The same procedures were applied not only by our team but also by the other studies used in this compilation. The catalogue presented in Table A.2 is structured as follows:

- ID: cluster designations from different catalogues.

- Cluster radius: distance $r$ in arcminutes from the cluster's centre up to the region where the stellar density equals that of the background.

- Angular deprojected distance: distance, measured in degrees, from the LMC optical centre to the cluster.

- $E(B-V)$ : cluster reddening.

- Age $_{\mathrm{I}}$ age in gigayears determined from isochrone fittings.

- $[\mathrm{Fe} / \mathrm{H}]_{\mathrm{I}}$ : metallicity determined from isochrone fittings.

- Age ${ }_{I I}$ : age in gigayears derived from the $\delta T_{1}$ method.

- $[\mathrm{Fe} / \mathrm{H}]_{\mathrm{II}}$ : metallicity estimated from the SGB procedure of Geisler \& Sarajedini (1999).

- Notes: letters a, b and c indicate that the clusters have also been studied in other photometric systems. The letter $\mathrm{m}$ denotes that the cluster is part of a binary or a multiple system (Dieball et al. 2002).

- Ref: references to the works from which we took the fundamental parameters determined by other authors in the Washington photometric system.

\section{Statistical analysis}

\subsection{Empirical cumulative distribution function (ECDF)}

Although the age and metallicity distributions of the LMC SCs can be examined and compared by computing their respective histograms, the corresponding empirical cumulative distribution functions (ECDFs) are preferred since they are independent of the particular selection of the binning function employed to build the histograms. The ECDF of a random sample of observations $x_{1}, x_{2}, \ldots, x_{n}$ is a function $F_{n}(t)$ given by the fraction of objects in the sample that are equal to or lower than an arbitrary value $t$. This function is equivalent to the original data. Its use avoids the loss of information brought about by the rounding off that results from placing the data in integer bin units when histograms are constructed (e.g. Drion 1952).

The ECDF can also be used to compare two samples and to assess whether they are intrinsically different or just random realizations of the same parent distribution that appear different because of the stochastic nature of the data. The maximum difference between the two ECDFs, denoted by D, is commonly
Table 2. Designation of the different samples used.

\begin{tabular}{lcc}
\hline \hline Name & Description & Number of SCs \\
\hline S0 & Full LMC cluster sample & 1970 \\
S1 & Our cluster sample & 82 \\
S2 & Full Washington cluster sample & 277 \\
S3 & S2-S1 & 195 \\
\hline
\end{tabular}

used as an indicator of the distinctiveness of the two data sets. This is the basis of the Kolmogorov-Smirnov test or KS test (e.g. Press et al. 1992), which allows one to quantitatively contrast the hypothesis that the two samples are drawn from the same parent distribution to a given significance level, with the alternative hypothesis that the two samples are not taken from the same population. The statistic of this test has a known distribution that permits computing the $p$-value, i.e., the probability of obtaining, in two random samples, a value of the variable $D$ equal to or larger than the one observed for the two particular data sets. Because it is nearly distribution free, this statistic is fairly easy to compute (Ross 2012).

\subsection{Statistical results}

We adopted the above defined ECDF to study the age and metallicity results obtained for different LMC cluster samples. The ECDF was also used to analyse the advantages of employing different sets of theoretical isochrones. Four different LMC SC samples are considered for our statistical analysis. The first of these samples, called S0, includes all the SCs whose ages and metallicities have been determined by any other procedure. A second sample (S1) includes the 82 SCs of our own recent sample. A third (S2) is made up of all 277 SCs that have been observed and studied in the Washington photometric system to date, i.e. this catalogue. A fourth sample (S3) represents the difference S2-S1. Table 2 shows the designations given to the different LMC cluster samples considered.

\subsubsection{Metallicity distributions}

Panel (a) of Fig. 2 exhibits the metallicity $\left([\mathrm{Fe} / \mathrm{H}]_{\mathrm{I}}\right)$ histograms (number of clusters per metallicity interval) corresponding to cluster samples S2 (empty bars) and S1 (dashed bars), respectively. Although the metallicity distribution of the clusters belonging to $\mathrm{S} 2$ is narrower than that of cluster sample $\mathrm{S} 1$, the locations of the peaks of these two distributions are very similar within the errors $(\langle[\mathrm{Fe} / \mathrm{H}]\rangle=-0.39$ and -0.42 for $\mathrm{S} 2$ and $\mathrm{S} 1$, respectively). In fact, a t-test for the difference of the mean metallicity values yields a result consistent with zero, to a statistical significance level of $95 \%$. Given the statistical evidence, it is not possible to conclude that there is a significant difference between samples $\mathrm{S} 1$ and $\mathrm{S} 2$. This suggests that $\mathrm{S} 1$ and $\mathrm{S} 2$ come from the same parent distribution as far as metallicity is concerned. Also, the kurtosis is positive for the two samples (5.5 and 3.2 for S1 and S2, respectively), which indicates that although the S2 distribution is more concentrated around its mean value, both $\mathrm{S} 1$ and S2 are narrower distributions than would be expected from a Gaussian distribution. More than $60 \%$ of the clusters in S2, for example, have metallicities in the $[-0.45,-0.35]$ range, in contrast with less than $30 \%$ of the clusters in S1, for the same metallicity range. This difference may be due to the fact that for most of the clusters in the S2 sample, metallicities have a fixed value of -0.4 dex. In panel (b) of the same figure, the metallicity ECDFs obtained using the Girardi et al. (2002) and Bressan et al. (2012) isochrone sets are shown by dashed and solid lines, respectively. The Girardi et al. (2002) models only 
T. Palma et al.: Catalogue of LMC star clusters observed in the Washington system.
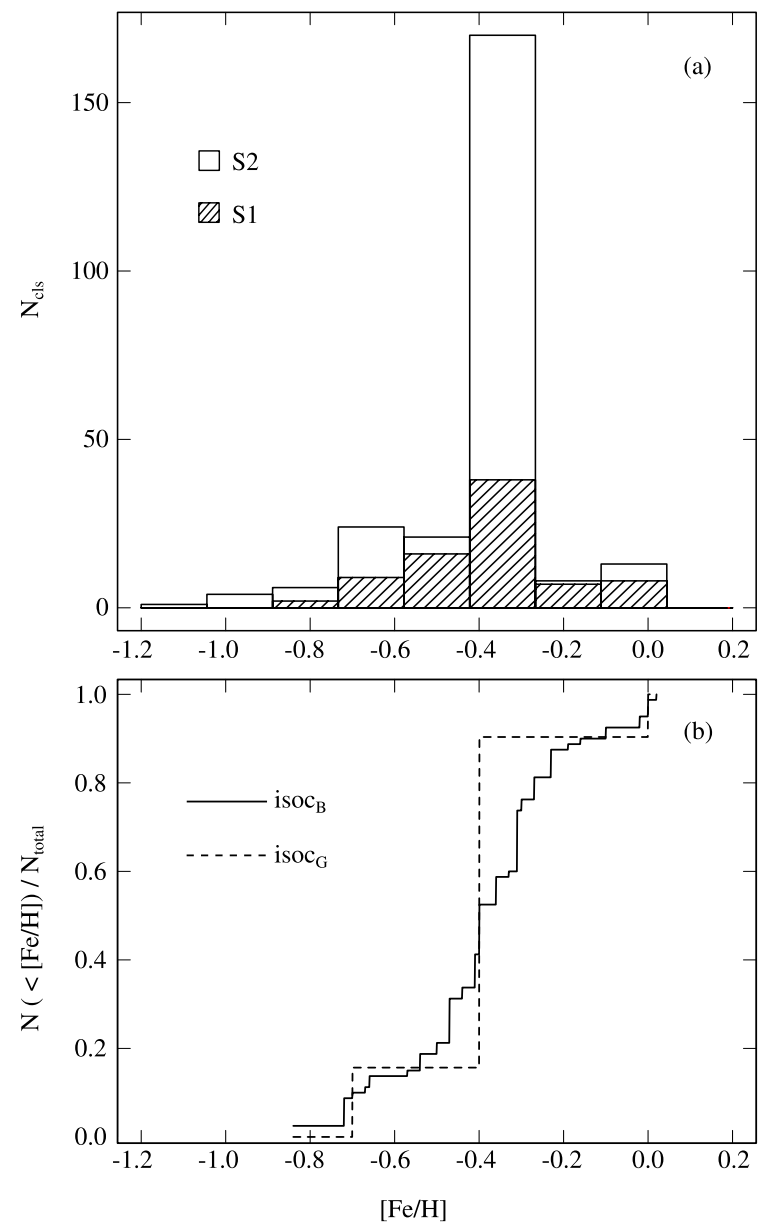

Fig. 2. Panel a): histograms showing the metallicity distributions of LMC SCs in the S2 (empty bars) and S1 (dashed bars) cluster samples, respectively. Panel b): comparison of metallicity ECDFs obtained for our own cluster sample S1 using sets of isochrones computed by Girardi et al. (2002, dashed line) and Bressan et al. (2012, solid line).

admit the adoption of discrete metallicity values $(-0.7,-0.4$ and 0.0 in our case). There is a large jump in the metallicity ECDF at $[\mathrm{Fe} / \mathrm{H}]=-0.4$ as this is precisely the most frequent value. On the other hand, the metallicities obtained by using Bressan et al. (2012) isochrones are distributed over different values in the same metallicity range. In this case, the metallicity ECDF is represented by a smoother curve and the metallicity mode is equal to -0.36 . The difference between this value and the above mentioned -0.4 exceeds the mean metallicity error as a consequence of the procedures used to estimate the metallicities from isochrone fittings.

\subsubsection{Age distributions}

The age histograms and age ECDFs for different LMC cluster samples are shown in Fig. 3. In the upper panel (a), S0 and S2 samples are represented by empty bars and dashed bars, respectively. It can be clearly seen that the ages at which these two distributions reach their peak values are different. Indeed, the corresponding age of the S2 peak distribution is about $1.90 \mathrm{Gyr}$ larger than that of S0. However, the shapes of these two distributions are fairly similar, since their skewness values are nearly the same. Indeed, while $67 \%$ of the clusters in S2 are younger than $1 \mathrm{Gyr}$, this percentage in the full cluster sample S0 rises to $90 \%$. This difference may result from the differing selection of targets
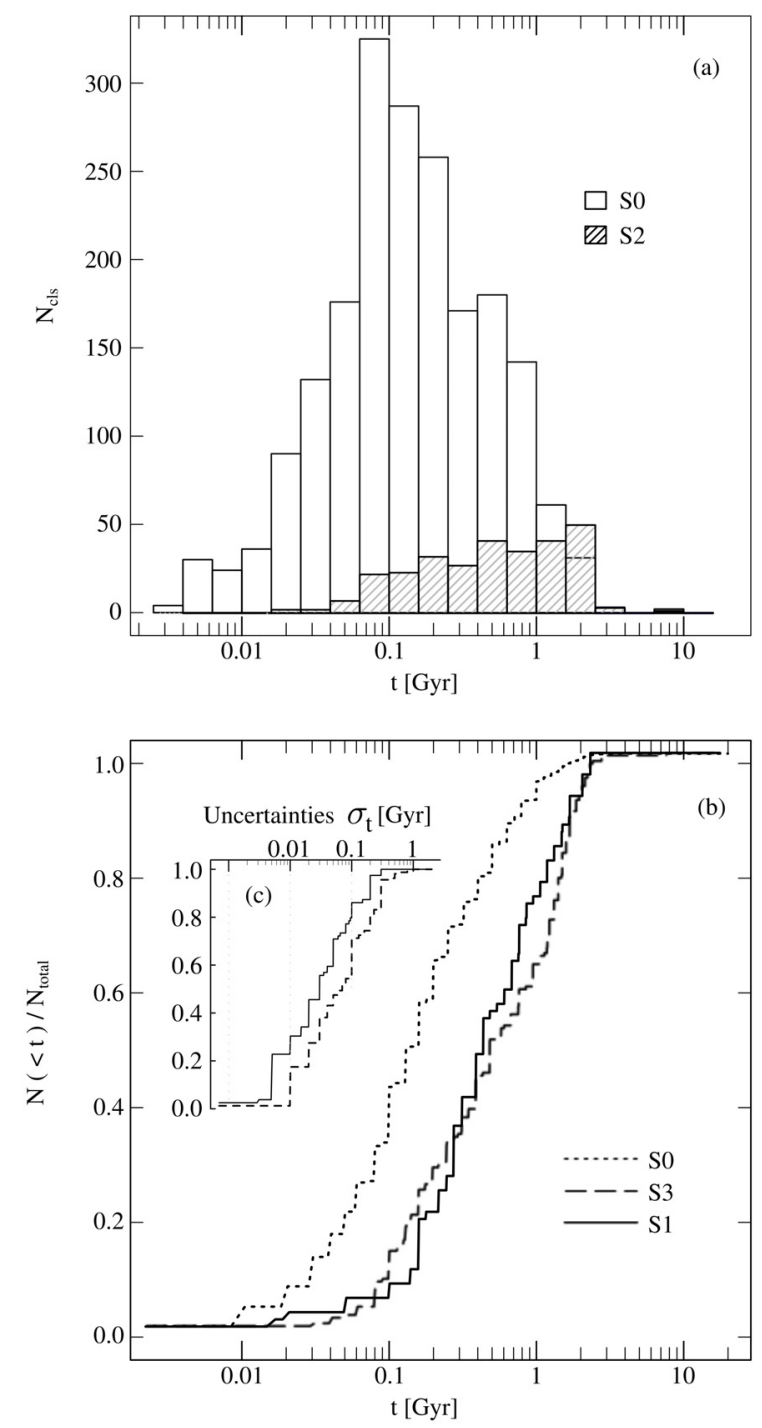

Fig. 3. Panel a): histograms showing the age distributions obtained for the S0 (empty bars) and S2 (dashed bars) cluster samples. Panel b): age ECDFs for S1 (solid line), its complementary sample S3 (dashed line), and S0 (short dashed line) cluster samples. The cumulative distribution estimates of age uncertainties are also shown in the inset.

made for each sample. In fact, most of the clusters included in S0, for example, have been studied by Pietrzyński \& Udalski (2000) and Glatt et al. (2010) who selected clusters younger than 1 Gyr. The age shift could also partially reflect the fact that cluster ages in S1 and S3 were estimated only from Washington photometric data, while those in S0 were obtained using different photometric systems (UBV, Washington, etc.). Age dispersions are also different, being $10 \%$ larger in S0 than in S2. To quantify this difference, we performed a test for the ratio of variances of these two distributions, thus obtaining a difference of 1 to a statistical significance level of $95 \%$. In the lower panel (b) of Fig. 3, different age ECDFs are shown. In the inset plot, the age error distributions for $\mathrm{S} 1$ and $\mathrm{S} 3$ samples are presented. The age uncertainties are clearly smaller in the S1 sample. Indeed, $80 \%$ of S1 clusters have uncertainties lower than $0.08 \mathrm{Gyr}$, while the lower tail of the uncertainties in the $\mathrm{S} 3$ sample reaches $0.3 \mathrm{Gyr}$. The mean values of these two distributions differ by $0.06 \mathrm{Gyr}$, which implies that the mean age uncertainty in S3 is more than twice the value of S1. A KS test rejects the possibility that both distributions are consistent with a $p$-value of 0.003 . 


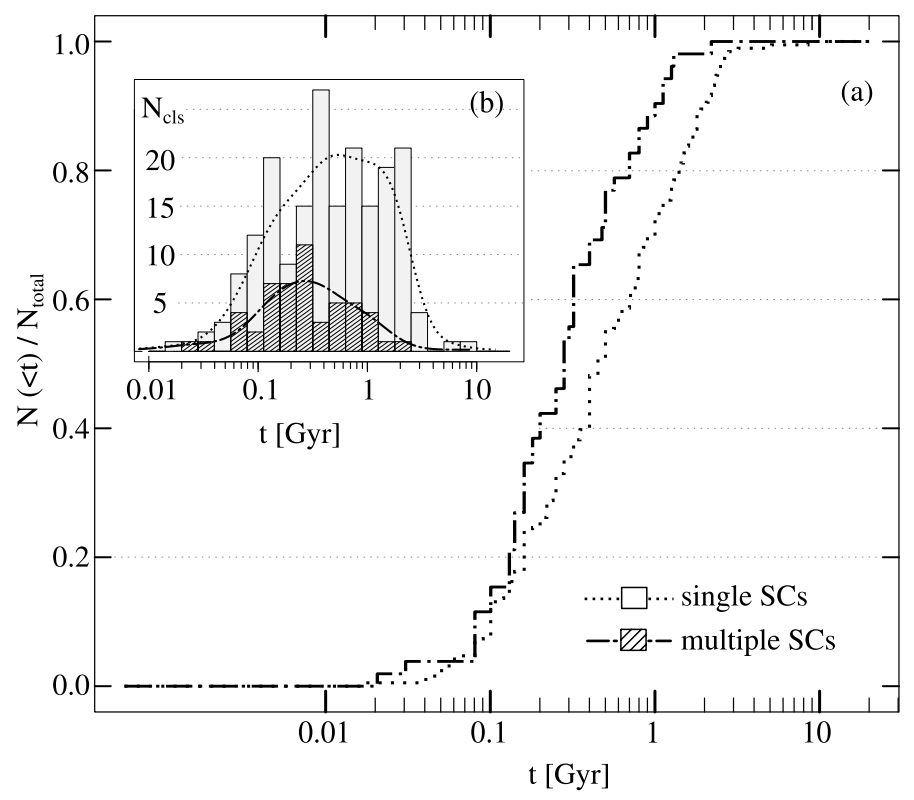

Fig. 4. Age distributions for multiple and single LMC clusters. The empirical cumulative distributions for multiple systems (dash-dotted line) and single SCs (dotted line) are shown. In the inset panel (b), the corresponding age histograms are shown (empty and shaded bars for single and multiple SCs, respectively) together with the kernel density estimations of both distributions (solid lines).

\subsubsection{Age and characteristics of single and multiple star clusters}

We also examined the differences existing between the ages of single and multiple systems in the LMC. According to Dieball et al. (2002), multiple systems appear to be formed by close pairs or several clusters on the plane of the sky as a result of projection effects. In panel (a) of Fig. 4, the ECDFs for multiple (dash-dotted line) and single SCs (dotted line) are plotted. The corresponding age histograms as well as the kernel density estimations for these two distributions are also shown in the inset panel (b). It can be clearly seen in Fig. 4 that single LMC SCs are typically older than multiple SCs. This difference is reflected both in the means and the shapes of the distributions. The Welch t-test (Welch 1947), designed to test if two samples have the same mean, is more reliable than the Student t-test applied when the two samples have different sizes and unknown variances which are also suspected of being different. We used the Student test to measure the difference in the age values of single and multiple systems. We found that the statistic for the difference of the sample means belongs to the confidence interval $(0.11,0.37)$ to a statistical significance level of $95 \%$. The mean age values are 0.48 and 0.27 Gyr for single and multiple star cluster samples, respectively. The F-test (Snedecor \& Cochran 1989) is useful to determine whether two populations have similar dispersions. The F-test uses the ratio of the sample variances as the test statistic, which follows an F distribution and thus permits testing the hypothesis that the ratio of the variances equals one. Although the variance for the sample of single SCs is approximately $40 \%$ larger than that of multiple $\mathrm{SCs}$, the F statistic for the quotient of the variances is not conclusive when discarding the null hypothesis of the variances being equal $\left(v_{1} / v_{2}=1.43, p=0.132\right)$. In addition, both multiple and single SCs exhibit asymmetrical distributions in $\log ($ age $)$, the latter being slightly more asymmetric than that of the multiple SCs. This is quantified by the skewness values of -0.212 and -0.196 obtained for single and multiple SCs, respectively,
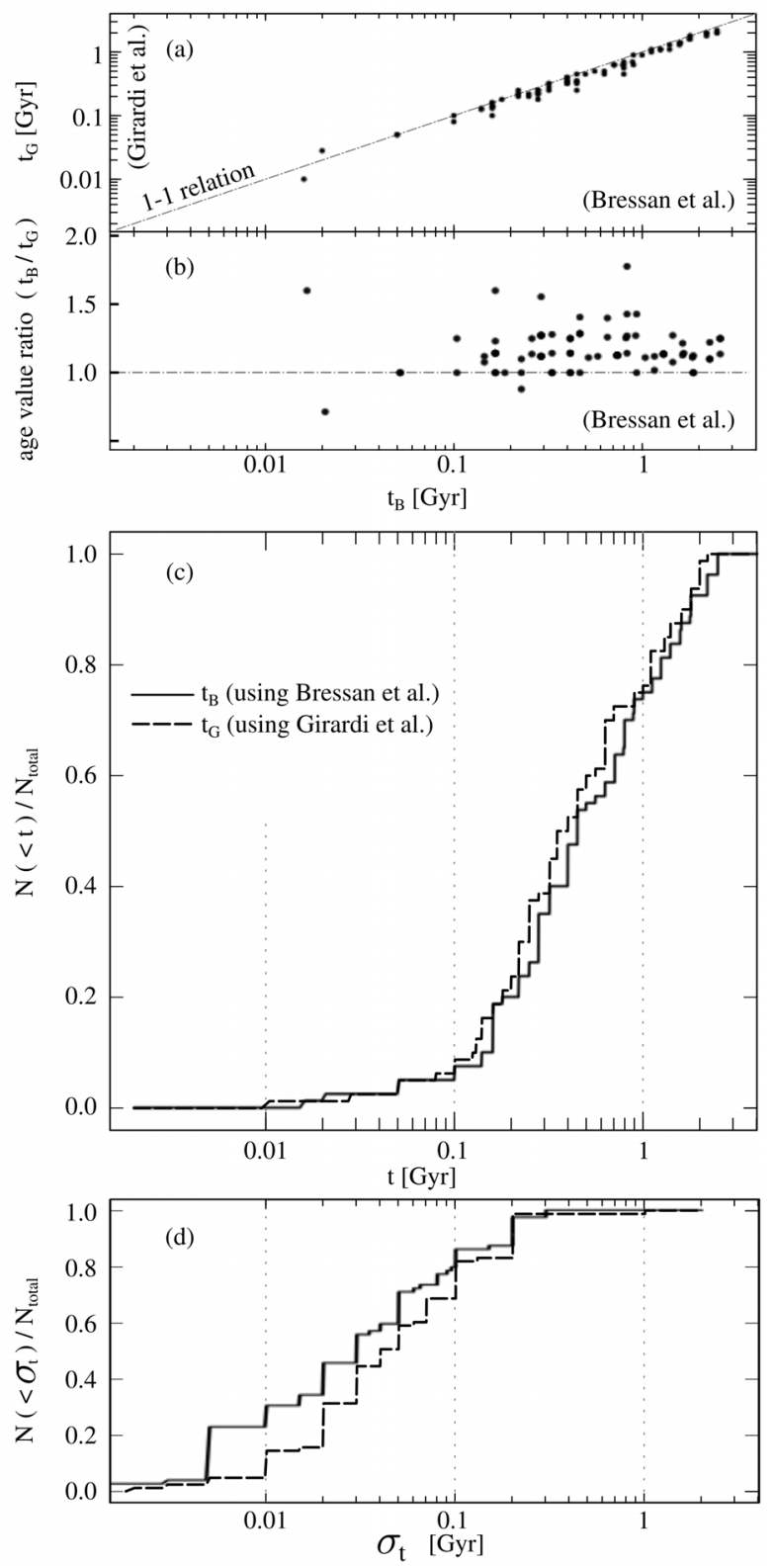

Fig. 5. Age determinations using the Girardi et al. (2002) (dashed line) or Bressan et al. (2012) (solid line) set of isochrones. In panel a), the correlation between age estimates determined using both sets of isochrones is shown. A linear fit (not shown in the diagram) yields a slope of 0.98 , which implies a slight bias towards greater age estimations when computed with the Bressan et al. models. A one-to-one relation (dot-dashed line) is also shown for the sake of comparison. In panel b), the ratio between ages obtained using Bressan et al. and Girardi et al. models is presented. Values larger than 1 mean that the Bressan et al. age estimates are larger. In panel c), the age ECDFs using the Bressan et al. isochrones (solid line) and the Girardi et al. isochrones (dashed line) are plotted. The uncertainty distributions are represented by the corresponding cumulative distributions in the bottom panel d).

meaning that the tail of older clusters appears to be flatter and falls more abruptly. In spite of the distribution shapes appearing wide, kurtosis values are 2.42 and 3.02 for simple and multiple SCs, respectively. These values indicate that the tails of the distributions are truncated with respect to a Gaussian distribution. The kernel density estimations of the two age distributions are also shown in panel (b) of Fig. 4. This does not depend on the bin size used to build the age histogram and contributes to enhancing the distribution asymmetry, especially for single SCs. 
T. Palma et al.: Catalogue of LMC star clusters observed in the Washington system.

\subsubsection{Age determinations with different models}

The ages resulting from isochrone fittings when different models of the Padova group are used will now be compared. We call the ages estimated using the Girardi et al. (2002) and Bressan et al. (2012) models $t_{\mathrm{G}}$ and $t_{\mathrm{B}}$, respectively. In order to compare the resulting ages in these two cases, we show the relation existing between both age determinations in panels (a) and (b) of Fig. 5. In panels (c) and (d) of the same figure, the age ECDFs and the cumulative distributions of age determination uncertainties are presented. As shown in the upper panel (a), if a logarithmic age relation is adopted, the differences between the resulting ages when one or the other set of isochrones is used are not very noticeable. A linear fit in panel (a) yields a slope $\alpha=0.98$, slightly smaller than $\alpha=1$, which would correspond to the absence of systematic differences between the two models. However, differences in some objects arise when the ratio of age determinations is considered. Panel (b) exhibits the behaviour as a function of age of the ratio $t_{\mathrm{B}} / t_{\mathrm{G}}$ between ages derived using these two models. Values of this ratio larger than 1 indicate that the cluster age determinations using the Bressan et al. isochrones are larger than those using the Girardi et al. isochrones. As can be seen in panel (b), $t_{\mathrm{G}}$ values have been generally underestimated compared to $t_{\mathrm{B}}$ values. In fact, only in $2.5 \%$ of the studied cluster sample can we find that $t_{\mathrm{G}}>t_{\mathrm{B}}$, which means that only 2 out of the 82 clusters of our sample fulfil this relation. Eleven of the clusters have ages that are virtually identical, whereas in the remaining $87 \%$ the relation $t_{\mathrm{B}}>t_{\mathrm{G}}$ holds. The excess in age, measured in Gyr, is at least $12 \%$ for 50 out of the 82 clusters of the sample S1 and even larger than $50 \%$ for the 5 clusters exhibiting the greatest differences. As shown in panel (c) of Fig. 5, the shapes of the two distributions in logarithmic scale are similar. The small shift between these two distributions accounts for the previously mentioned differences. It is seen in panel (d) that not only are $t_{\mathrm{B}}$ values typically larger than those of $t_{\mathrm{G}}$, but also that the Bressan et al. age uncertainties are clearly smaller than the corresponding values of Girardi et al. In panel (d), a KS test yields $p=0.125$ with $t$ in Gyr units. For example, half of the age error values obtained using the Girardi et al. isochrones are smaller than $0.04 \mathrm{Gyr}$, while the median of the error values obtained from Bressan et al. isochrones is nearly 0.03 Gyr. Even if the errors involved when ages are determined using one or the other set of isochrones are almost the same, the "more continuous" distribution of the Bressan et al. metallicities leads to more precise fittings and hence to more accurately determined cluster parameters. We would like to point out that while there are global differences in age determinations, when individual clusters are considered, the ages inferred from the two models turn out to be practically indistinguishable, as can be observed in Table A.2.

Acknowledgements. We gratefully acknowledge financial support from the Argentinian institutions CONICET, FONCYT and SECYT (Universidad Nacional de Córdoba). Support for T.P. is provided by the Ministry of Economy, Development, and Tourism's Millennium Science Initiative through grant IC 120009, awarded to The Millennium Institute of Astrophysics, MAS. D.G. gratefully acknowledges support from the Chilean BASAL Centro de Excelencia en Astrofísica y Tecnologías Afines (CATA) grant PFB-06/2007. This work is based on observations made at Cerro Tololo Inter-American Observatory, which is operated by AURA, Inc., under cooperative agreement with the National Science Foundation. Part of this work was supported by the German Deutsche Forschungsgemeinschaft, DFG project number Ts $17 / 2-1$. We especially thank the referee, Mario Mateo, for his valuable comments and suggestions about the manuscript. Plots were generated using $\mathrm{R}$ software and post-processed with Inkscape. This research has made use of NASA's Astrophysics Data System.

\section{References}

Bhatia, R. K., Read, M. A., Hatzidimitriou, D., \& Tritton, S. 1991, A\&AS, 87, 335

Bica, E., Geisler, D., Dottori, H., et al. 1998, AJ, 116, 723

Bica, E., Schmitt, H. R., Dutra, C. M., \& Oliveira, H. L. 1999, AJ, 117, 238

Bica, E., Bonatto, C., Dutra, C. M., \& Santos Jr., J. F. C. 2008, MNRAS, 389, 678

Bok, B. J. 1966, ARA\&A, 4, 95

Bothun, G. D., \& Thompson, I. B. 1988, AJ, 96, 877

Bressan, A., Marigo, P., Girardi, L., et al. 2012, MNRAS, 427, 127

Burstein, D., \& Heiles, C. 1982, AJ, 87, 1165

Canterna, R. 1976, AJ, 81, 228

Choudhury, S., Subramaniam, A., \& Piatti, A. E. 2015, AJ, 149, 52

Clariá, J. J., Piatti, A. E., Parisi, M. C., \& Ahumada, A. V. 2007, MNRAS, 379, 159

Clariá, J. J., Piatti, A. E., Santos, Jr., J. F. C., et al. 2005, Boletín AAA, 48, 140

Da Costa, G. S., \& Armandroff, T. E. 1990, AJ, 100, 162

Dieball, A., Müller, H., \& Grebel, E. K. 2002, A\&A, 391, 547

Drion, E. F. 1952, Ann. Math. Statist., 23, 563

Geisler, D. 1987, AJ, 93, 1081

Geisler, D., \& Sarajedini, A. 1999, AJ, 117, 308

Geisler, D., Clariá, J. J., \& Minniti, D. 1991, AJ, 102, 1836

Geisler, D., Bica, E., Dottori, H., et al. 1997, AJ, 114, 1920

Geisler, D., Piatti, A. E., Bica, E., \& Clariá, J. J. 2003, MNRAS, 341, 771

Girardi, L., Bertelli, G., Bressan, A., et al. 2002, A\&A, 391, 195

Glatt, K., Grebel, E. K., \& Koch, A. 2010, A\&A, 517, A50

Harris, J., \& Zaritsky, D. 2009, AJ, 138, 1243

Hodge, P. W. 1975, Irish Astron. J., 12, 77

Hodge, P. W. 1988, PASP, 100, 1051

Hodge, P. W., \& Sexton, J. A. 1966, AJ, 71, 363

Holtzman, J. A., Gallagher, III, J. S., Cole, A. A., et al. 1999, AJ, 118, 2262

Kennicutt, Jr., R. C., Bresolin, F., Bomans, D. J., Bothun, G. D., \& Thompson, I. B. 1995, AJ, 109, 594

Kontizas, E., Metaxa, M., \& Kontizas, M. 1988, AJ, 96, 1625

Kontizas, M., Morgan, D. H., Hatzidimitriou, D., \& Kontizas, E. 1990, A\&AS, 84,527

Lejeune, T., \& Schaerer, D. 2001, A\&A, 366, 538

Lyngå, G., \& Westerlund, B. E. 1963, MNRAS, 127, 31

Olsen, K. A. G., \& Salyk, C. 2002, AJ, 124, 2045

Olszewski, E. W., Harris, H. C., Schommer, R. A., \& Canterna, R. W. 1988, AJ, 95,84

Palma, T., Clariá, J. J., Geisler, D., et al. 2011, Boletín AAA, 54, 195

Palma, T., Clariá, J. J., Geisler, D., Piatti, A. E., \& Ahumada, A. V. 2013, A\&A, 555, A 131

Palma, T., Clariá, J. J., Geisler, D., Gramajo, L. V., \& Ahumada, A. V. 2015, MNRAS, 450, 2122

Parker, J. W., Hill, J. K., Cornett, R. H., et al. 1998, AJ, 116, 180

Piatti, A. E. 2011, MNRAS, 418, L40

Piatti, A. E. 2012, A\&A, 540, A58

Piatti, A. E. 2014, MNRAS, 440, 3091

Piatti, A. E., \& Bica, E. 2012, MNRAS, 425, 3085

Piatti, A. E., Sarajedini, A., Geisler, D., Bica, E., \& Clariá, J. J. 2002, MNRAS, 329,556

Piatti, A. E., Bica, E., Geisler, D., \& Clariá, J. J. 2003a, MNRAS, 344, 965 Piatti, A. E., Geisler, D., Bica, E., \& Clariá, J. J. 2003b, MNRAS, 343, 851

Piatti, A. E., Clariá, J. J., Parisi, M. C., \& Ahumada, A. V. 2009a, New Astron., 14,97

Piatti, A. E., Geisler, D., Sarajedini, A., \& Gallart, C. 2009b, A\&A, 501, 585

Piatti, A. E., Clariá, J. J., Parisi, M. C., \& Ahumada, A. V. 2011, PASP, 123, 519

Pietrzyński, G., \& Udalski, A. 2000, Acta Astron., 50, 337

Pietrzyński, G., Udalski, A., Kubiak, M., et al. 1998, Acta Astron., 48, 175

Pietrzyński, G., Udalski, A., Kubiak, M., et al. 1999, Acta Astron., 49, 521

Popescu, B., Hanson, M. M., \& Elmegreen, B. G. 2012, ApJ, 751, 122

Press, W. H., Flannery, B. P., Teukolsky, S. A., \& Vetterling, W. T. 1992, Numerical Recipes in Fortran 77: The Art of Scientific Computing, 2nd edn. (Cambridge University Press)

Ross, S. M. 2012, Simulation (Academic Press)

Saha, A., Olszewski, E. W., Brondel, B., et al. 2010, AJ, 140, 1719

Schlegel, D. J., Finkbeiner, D. P., \& Davis, M. 1998, ApJ, 500, 525

Shapley, H., \& Lindsay, E. M. 1963, Irish Astronomical Journal, 6, 74

Smecker-Hane, T. A., Cole, A. A., Gallagher, III, J. S., \& Stetson, P. B. 2002, ApJ, 566, 239

Snedecor, G., \& Cochran, W. G. 1989, Statistical Methods (Iowa State University Press)

Subramanian, S., \& Subramaniam, A. 2009, A\&A, 496, 399

Welch, B. L. 1947, Biometrika, 34, 28 
Appendix A: Additional tables

Table A.1. LMC star clusters observed in the Washington photometric system.

\begin{tabular}{|c|c|c|c|c|c|}
\hline Star cluster $^{a}$ & $\begin{array}{c}\alpha_{2000} \\
(\mathrm{hms})\end{array}$ & $\begin{array}{c}\delta_{2000} \\
(\mathrm{dms})\end{array}$ & $\begin{array}{c}l \\
(\mathrm{deg})\end{array}$ & $\begin{array}{c}b \\
(\mathrm{deg})\end{array}$ & $\begin{array}{c}r^{b} \\
\text { (arcmin) }\end{array}$ \\
\hline HS 8, KMHK 5 & 043040 & -665725 & 278.862 & -38.343 & 0.40 \\
\hline SL 5, LW 8, KMHK 14 & 043538 & -734354 & 286.402 & -35.237 & 0.60 \\
\hline NGC 1644, SL 9, LW 11, ESO 84-30, KMHK 18 & 043739 & -661158 & 277.649 & -37.963 & 1.65 \\
\hline SL 8, LW 13, KMHK 21 & 043752 & -690142 & 280.975 & -36.949 & 0.75 \\
\hline SL 13, LW 17, KMHK 31 & 043942 & -740102 & 286.573 & -34.861 & 0.65 \\
\hline КМНК 58 & 044314 & -734843 & 286.224 & -34.721 & 0.43 \\
\hline КМHK 72 & 044605 & -665441 & 278.156 & -36.940 & 0.33 \\
\hline SL 33, LW 59, KMHK 91 & 044625 & -723406 & 284.717 & -34.986 & 0.55 \\
\hline SL 35, LW 58, KMHK 84 & 044640 & -674107 & 279.052 & -36.645 & 0.44 \\
\hline КМHK 95 & 044726 & -673936 & 278.994 & -36.584 & 0.23 \\
\hline SL 41, LW 64, KMHK 105 & 044730 & -723518 & 284.704 & -34.903 & 0.72 \\
\hline NGC 1697, SL 44, ESO 56-5, KMHK 110 & 044837 & -683331 & 280.011 & -36.196 & 1.15 \\
\hline KMHK 123 & 044900 & -723824 & 284.713 & -34.780 & 0.30 \\
\hline KMHK 112 & 044907 & -672030 & 278.556 & -36.528 & 0.50 \\
\hline KMHK 128 & 044914 & -720324 & 285.177 & -34.613 & 0.26 \\
\hline SL 48, LW 68, KMHK 133 & 044927 & -724654 & 284.859 & -34.698 & 0.45 \\
\hline LW 69, KMHK 137 & 044941 & -721450 & 284.243 & -34.873 & 0.28 \\
\hline KMHK 151 & 045021 & -724936 & 284.881 & -34.619 & 0.28 \\
\hline BSDL 77 & 045029 & -671936 & 278.489 & -36.407 & 0.30 \\
\hline SL 54, LW 78, KMHK 162 & 045048 & -723436 & 284.582 & -34.677 & 0.55 \\
\hline BSDL 87 & 045058 & -673636 & 278.808 & -36.279 & 0.25 \\
\hline HS 38, КMHК 148 & 045111 & -673201 & 278.710 & -36.282 & 0.35 \\
\hline HS 41, KMHK 158 & 045130 & -672715 & 278.605 & -36.276 & 0.29 \\
\hline KMHK 183 & 045141 & -721313 & 284.147 & -34.739 & 0.36 \\
\hline SL 73, LW 86, KMHK 214 & 045245 & -723105 & 284.454 & -34.561 & 0.34 \\
\hline SL 72, LW 87, KMHK 217 & 045254 & -721023 & 284.055 & -34.668 & 0.43 \\
\hline KMHK 229 & 045352 & -693414 & 281.016 & -35.435 & 0.40 \\
\hline BSDL 192 & 045405 & -694054 & 281.138 & -35.382 & 0.16 \\
\hline BSDL 194 & 045405 & -694530 & 281.227 & -35.359 & 0.21 \\
\hline NGC 1751, SL 89, ESO 56-23, KMHK 239 & 045412 & -694825 & 281.280 & -35.334 & 0.75 \\
\hline SL 96, H88-25, KMHK 256 & 045501 & -674251 & 278.795 & -35.880 & 0.41 \\
\hline H88-26 & 045503 & -675752 & 279.089 & -35.806 & 0.45 \\
\hline $\mathrm{H} 88-32$ & 045539 & -674334 & 278.788 & -35.819 & 0.21 \\
\hline H88-34, КMHK 285, MSX LMC 1238 & 045539 & -674919 & 278.900 & -35.793 & 0.29 \\
\hline КMHK 286 & 045542 & -674654 & 278.851 & -35.799 & 0.38 \\
\hline BSDL 268 & 045552 & -694221 & 281.110 & -35.227 & 0.26 \\
\hline BRHT 60b, H88-41, KMHK 309s & 045626 & -675619 & 279.013 & -35.689 & 0.30 \\
\hline NGC 1764, SL 115, KMHK 308 & 045628 & -674146 & 278.725 & -35.754 & 0.55 \\
\hline H88-40, КМНК 310 & 045629 & -673722 & 278.638 & -35.772 & 0.38 \\
\hline SL 124w, KMHK 324w & 045629 & -695900 & 281.413 & -35.094 & 0.29 \\
\hline SL 124e, KMHK 324e & 045632 & -695854 & 281.409 & -35.090 & 0.29 \\
\hline КМHK 335 & 045651 & -700603 & 281.537 & -35.029 & 0.30 \\
\hline BRHT 45b & 045652 & -680020 & 279.079 & -35.632 & 0.25 \\
\hline HS 72, BRHT 45a, KMHK 326 & 045654 & -680008 & 279.073 & -35.630 & 0.31 \\
\hline BSDL 320 & 045708 & -700642 & 281.542 & -35.002 & 0.20 \\
\hline SL 126, ESO 85-21, КMHK 322 & 045722 & -623205 & 272.479 & -36.910 & 0.65 \\
\hline SL 132, KMHK 348 & 045726 & -674107 & 278.681 & -35.668 & 0.50 \\
\hline SL 133, LW 99, KMHK 337 & 045734 & -651600 & 275.788 & -36.273 & 0.68 \\
\hline H88-52, КМHK 365 & 045810 & -680337 & 279.102 & -35.500 & 0.45 \\
\hline H88-55, КМHK 367 & 045815 & -674602 & 278.753 & -35.571 & 0.53 \\
\hline BSDL 341 & 045815 & -680257 & 279.086 & -35.495 & 0.28 \\
\hline SL 151, KMHK 388 & 045851 & -695728 & 281.311 & -34.908 & 0.63 \\
\hline H88-67 & 045854 & -675049 & 278.827 & -35.491 & 0.26 \\
\hline
\end{tabular}

Notes. ${ }^{(a)}$ Cluster identifications from (SL): Shapley \& Lindsay (1963); (LW): Lyngå \& Westerlund (1963); (HS): Hodge \& Sexton (1966); (C): Hodge (1975); H88: Hodge (1988); (OHSC): Olszewski et al. (1988); (KMK): Kontizas et al. (1988); (KMHK): Kontizas et al. (1990); (BRHT): Bhatia et al. (1991); (LOGLE): Pietrzyński et al. (1998, 1999); (BSDL): Bica et al. (1999). ${ }^{(b)}$ Obtained from Bica et al. (2008). 
T. Palma et al.: Catalogue of LMC star clusters observed in the Washington system.

Table A.1. continued.

\begin{tabular}{|c|c|c|c|c|c|}
\hline Star cluster ${ }^{a}$ & $\begin{array}{c}\alpha_{2000} \\
(\mathrm{hms})\end{array}$ & $\begin{array}{c}\delta_{2000} \\
(\mathrm{dms})\end{array}$ & $\begin{array}{c}l \\
(\mathrm{deg})\end{array}$ & $\begin{array}{c}b \\
(\mathrm{deg})\end{array}$ & $\begin{array}{c}r^{b} \\
(\operatorname{arcmin})\end{array}$ \\
\hline SL 154, H88-73, KMHK 390 & 045915 & -675432 & 278.889 & -35.442 & 0.60 \\
\hline NGC 1793, SL 163, ESO 56-43, KMHK 405 & 045938 & -693322 & 280.816 & -34.957 & 0.60 \\
\hline NGC 1795, SL 165, ESO 56-44, KMHK411 & 045946 & -694804 & 281.100 & -34.876 & 0.68 \\
\hline SL 162, H88-79, KMHK 406 & 045953 & -675525 & 278.888 & -35.381 & 0.53 \\
\hline BRHT 62a, H88-84, KMHK 412 & 050004 & -674802 & 278.737 & -35.396 & 0.45 \\
\hline KMHK 506 & 050429 & -682055 & 279.257 & -34.859 & 0.34 \\
\hline BSDL 527 & 050434 & -681230 & 279.088 & -34.886 & 0.21 \\
\hline SL 218, LOGLE 80 & 050525 & -683004 & 279.411 & -34.738 & 0.46 \\
\hline NGC 1836, SL 223, ESO 56-31, BRHT 4a & 050536 & -683746 & 279.557 & -34.690 & 0.73 \\
\hline BRHT $4 \mathrm{~b}$, LOGLE 83 & 050540 & -683812 & 279.563 & -34.682 & 0.48 \\
\hline BSDL 594, LOGLE 87 & 050554 & -670258 & 277.678 & -35.038 & 0.43 \\
\hline NGC 1839, SL 226, ESO 56-63, LOGLE 93 & 050603 & -683737 & 279.542 & -34.650 & 0.80 \\
\hline HS 114, KMHK 533 & 050602 & -680135 & 278.831 & -34.798 & 0.43 \\
\hline NGC 1838, SL 225, ESO 56-64, LOGLE 97 & 050609 & -682645 & 279.325 & -34.686 & 0.63 \\
\hline HS 116, KMHK 536 & 050613 & -680353 & 278.873 & -34.772 & 0.26 \\
\hline SL 229, BRHT 29a, LOGLE 105 & 050625 & -682222 & 279.231 & -34.679 & 0.51 \\
\hline SL 230, BRHT 29b, OGLE 107 & 050632 & -682144 & 279.216 & -34.671 & 0.68 \\
\hline BSDL 631, LOGLE 109 & 050634 & -682538 & 279.292 & -34.653 & 0.23 \\
\hline H88-131, КМНК 544 & 050641 & -675028 & 278.596 & -34.781 & 0.35 \\
\hline LOGLE 122 & 050719 & -682054 & 279.179 & -34.605 & 0.12 \\
\hline BSDL 654, LOGLE 123 & 050721 & -664945 & 277.377 & -34.949 & 0.21 \\
\hline LOGLE 127 & 050732 & -673413 & 278.253 & -34.766 & 0.28 \\
\hline NGC 1846, SL 243, ESO 56-67, KMHK 557 & 050735 & -672739 & 278.119 & -34.786 & 1.9 \\
\hline SL 244 & 050737 & -683231 & 279.399 & -34.532 & 0.50 \\
\hline HS 121, КМНК 560 & 050746 & -675141 & 278.590 & -34.678 & 0.35 \\
\hline BSDL 665, LOGLE 130 & 050747 & -664753 & 277.329 & -34.914 & 0.21 \\
\hline BSDL 675, LOGLE 134 & 050756 & -672128 & 277.990 & -34.776 & 0.29 \\
\hline KMHK 575, LOGLE 139 & 050828 & -664614 & 277.278 & -34.854 & 0.47 \\
\hline KMHK 586 & 050851 & -675849 & 278.704 & -34.552 & 0.28 \\
\hline BSDL 716, GKK-O217 & 050853 & -680501 & 278.825 & -34.525 & 0.68 \\
\hline SL 263, LOGLE 144 & 050854 & -664708 & 277.285 & -34.809 & 0.24 \\
\hline GKK-O222 & 050900 & -675900 & 278.704 & -34.537 & 0.73 \\
\hline HS 131 & 050912 & -682639 & 279.244 & -34.414 & 0.20 \\
\hline HS 130, КМHK 588 & 050915 & -674200 & 278.362 & -34.577 & 0.28 \\
\hline SL 262, LW 146, ESO 119-40, KMHK 582 & 050921 & -622246 & 271.976 & -35.577 & 0.80 \\
\hline NGC 1852, SL 264, ESO 56-71, KMHK 594 & 050923 & -674642 & 278.450 & -34.547 & 0.95 \\
\hline BSDL 761 & 051002 & -664200 & 277.155 & -34.717 & 0.32 \\
\hline GKK-O220 & 051018 & -675100 & 278.512 & -34.447 & 0.78 \\
\hline HS 151 & 051030 & -682402 & 279.161 & -34.308 & 0.29 \\
\hline BSDL 779, LOGLE 182 & 051032 & -665624 & 277.428 & -34.619 & 0.22 \\
\hline SL 281, KMHK 616, LOGLE183 & 051033 & -670739 & 277.650 & -34.579 & 0.62 \\
\hline SL 290, KMHK 628 & 051036 & -702915 & 281.605 & -33.806 & 0.53 \\
\hline BSDL 783, LOGLE 186 & 051039 & -664345 & 277.174 & -34.651 & 0.26 \\
\hline NGC 1860, SL 284, ESO 56-75, LOGLE 187 & 051040 & -684513 & 279.570 & -34.212 & 0.55 \\
\hline BSDL794 & 051046 & -672906 & 278.069 & -34.483 & 0.19 \\
\hline H88-188, KMHK 622, LOGLE 191 & 051054 & -672816 & 278.049 & -34.474 & 0.30 \\
\hline HS 154, H88-189, KMHK 625, LOGLE 194 & 051056 & -673736 & 278.233 & -34.437 & 0.35 \\
\hline SL 293, KMHK 630 & 051109 & -674057 & 278.295 & -34.405 & 0.46 \\
\hline HS 156, H88-190, KMHK 632, LOGLE 199 & 051111 & -673737 & 278.227 & -34.414 & 0.25 \\
\hline NGC 1863, SL299, ESO 56-77, LOGLE 206 & 051140 & -684336 & 279.514 & -34.131 & 0.65 \\
\hline SL 300, H88-198, KMHK 638, LOGLE 207 & 051141 & -673356 & 278.142 & -34.381 & 0.46 \\
\hline NGC 1865, SL 307, ESO 56-78, LOGLE 221 & 051225 & -684619 & 279.549 & -34.055 & 0.70 \\
\hline SL 310, KMHK 652, LOGLE 224 & 051230 & -671728 & 277.797 & -34.359 & 0.43 \\
\hline NGC 1864, SL 309, ESO 56-79 & 051240 & -673724 & 278.187 & -34.276 & 0.51 \\
\hline BSDL 923 & 051343 & -672410 & 277.901 & -34.223 & 0.23 \\
\hline HS 178, КMHK 667 & 051348 & -663712 & 276.970 & -34.367 & 0.34 \\
\hline NGC 1885, SL 338, ESO 56-88, LOGLE 261 & 051507 & -685843 & 279.729 & -33.772 & 0.65 \\
\hline
\end{tabular}


Table A.1. continued.

\begin{tabular}{|c|c|c|c|c|c|}
\hline Star cluster ${ }^{a}$ & $\begin{array}{c}\alpha_{2000} \\
(\mathrm{hms})\end{array}$ & $\begin{array}{c}\delta_{2000} \\
(\mathrm{dms})\end{array}$ & $\begin{array}{c}l \\
(\mathrm{deg})\end{array}$ & $\begin{array}{c}b \\
(\mathrm{deg})\end{array}$ & $\begin{array}{c}r^{b} \\
(\operatorname{arcmin})\end{array}$ \\
\hline BSDL 1024, LOGLE 262 & 051515 & -685257 & 279.614 & -33.782 & 0.41 \\
\hline LOGLE 264 & 051521 & -690627 & 279.875 & -33.725 & 0.18 \\
\hline H88-232 & 051522 & -690232 & 279.798 & -33.737 & 0.23 \\
\hline BSDL 1035 & 051525 & -684052 & 279.373 & -33.808 & 0.23 \\
\hline HS 198 & 051526 & -690302 & 279.807 & -33.730 & 0.26 \\
\hline HS200, LOGLE 269 & 051536 & -690821 & 279.907 & -33.697 & 0.43 \\
\hline LOGLE 271 & 051539 & -685431 & 279.635 & -33.741 & 0.45 \\
\hline H88-238, LOGLE 276 & 051547 & -691439 & 280.027 & -33.659 & 0.38 \\
\hline H88-240, LOGLE 282 & 051604 & -690609 & 279.853 & -33.664 & 0.33 \\
\hline H88-245, LOGLE 288 & 051627 & -690449 & 279.819 & -33.635 & 0.26 \\
\hline H88-249 & 051631 & -691058 & 279.939 & -33.608 & 0.23 \\
\hline HS 205, LOGLE 290 & 051632 & -685507 & 279.627 & -33.660 & 0.55 \\
\hline H88-252 & 051643 & -691213 & 279.958 & -33.586 & 0.39 \\
\hline H88-253, LOGLE 296 & 051650 & -690335 & 279.786 & -33.605 & 0.38 \\
\hline LOGLE 297 & 051652 & -690413 & 279.798 & -33.600 & 0.12 \\
\hline SL 351 & 051656 & -684058 & 279.341 & -33.673 & 0.38 \\
\hline H88-259, LOGLE 306 & 051720 & -690925 & 279.890 & -33.542 & 0.51 \\
\hline H88-260, LOGLE 307 & 051720 & -691249 & 279.956 & -33.530 & 0.36 \\
\hline H88-261, LOGLE 310 & 051726 & -690655 & 279.838 & -33.542 & 0.51 \\
\hline SL 359, KMHK 727 & 051749 & -682822 & 279.075 & -33.635 & 0.60 \\
\hline H88-265, LOGLE 323 & 051805 & -691018 & 279.891 & -33.474 & 0.29 \\
\hline H88-269, LOGLE 337 & 051841 & -690446 & 279.770 & -33.439 & 0.33 \\
\hline LOGLE 340 & 051847 & -691332 & 279.939 & -33.402 & 0.32 \\
\hline $\mathrm{H} 88-270$ & 051847 & -691637 & 279.999 & -33.392 & 0.23 \\
\hline NGC 1917, SL 379, ESO 56-100, LOGLE 343 & 051902 & -690004 & 279.671 & -33.422 & 0.85 \\
\hline $\mathrm{H} 88-272$ & 051905 & -685214 & 279.515 & -33.445 & 0.26 \\
\hline OGLE 346 & 051909 & -691536 & 279.972 & -33.363 & 0.22 \\
\hline HS 228 & 051924 & -685252 & 279.522 & -33.415 & 0.30 \\
\hline SL 390, LOGLE 356 & 051954 & -685753 & 279.609 & -33.354 & 0.55 \\
\hline H88-276 & 051955 & -684807 & 279.418 & -33.384 & 0.26 \\
\hline LOGLE 363 & 052004 & -691555 & 279.959 & -33.282 & 0.15 \\
\hline SL 388, LW 186, ESO 85-72, KMHK 773 & 052005 & -632849 & 273.090 & -34.211 & 0.85 \\
\hline SL 397 & 052012 & -685415 & 279.534 & -33.341 & 0.50 \\
\hline H88-281 & 052021 & -691448 & 279.932 & -33.262 & 0.29 \\
\hline H88-285 & 052103 & -690551 & 279.741 & -33.229 & 0.38 \\
\hline SL 408A & 052105 & -690416 & 278.896 & -34.889 & 0.41 \\
\hline H88-286 & 052107 & -690809 & 279.787 & -33.216 & 0.20 \\
\hline H88-287 & 052109 & -690702 & 279.763 & -33.216 & 0.24 \\
\hline BSDL 1334, 88-259, LOGLE 306 & 052114 & -684700 & 279.369 & -33.271 & 0.23 \\
\hline HS 247 & 052145 & -685502 & 279.516 & -33.201 & 0.38 \\
\hline BSDL 1364 & 052146 & -684353 & 279.298 & -33.233 & 0.21 \\
\hline HS 253, LOGLE 403 & 052203 & -700244 & 280.833 & -32.962 & 0.29 \\
\hline KMK88-52 & 052217 & -700200 & 280.814 & -32.945 & 0.25 \\
\hline IC 2134, SL 437, LW 198, ESO 33-19, KMHK 864 & 052306 & -752648 & 287.049 & -31.698 & 0.70 \\
\hline HS 264, KMHK 845 & 052312 & -704640 & 281.666 & -32.725 & 0.40 \\
\hline SL 451, LW 206, KMHK 883 & 052413 & -753400 & 287.166 & -31.600 & 0.50 \\
\hline SL 446A, KMHK 858 & 052428 & -674343 & 278.067 & -33.156 & 0.46 \\
\hline SL 444, KMHK 861 & 052430 & -674041 & 278.006 & -33.161 & 0.54 \\
\hline LW 211, KMHK 901 & 052527 & -733413 & 284.858 & -31.979 & 0.33 \\
\hline SL 460, LOGLE 456 & 052528 & -694632 & 280.453 & -32.724 & 0.38 \\
\hline SL 469, LOGLE 467 & 052557 & -694504 & 280.415 & -32.687 & 0.43 \\
\hline КМHK 907 & 052612 & -705853 & 281.847 & -32.445 & 0.26 \\
\hline BSDL 1723, LOGLE 473 & 052624 & -694351 & 280.384 & -32.652 & 0.33 \\
\hline NGC 1969, SL 479, ESO 56-124 & 052634 & -695027 & 280.509 & -32.619 & 0.60 \\
\hline NGC 1971, SL 481, ESO 56-128 & 052646 & -695103 & 280.518 & -32.601 & 0.51 \\
\hline NGC 1972, SL 480, ESO 56-129 & 052649 & -695017 & 280.502 & -32.599 & 0.42 \\
\hline KMK88-57, LOGLE 483 & 052653 & -694854 & 280.473 & -32.596 & 0.29 \\
\hline
\end{tabular}


T. Palma et al.: Catalogue of LMC star clusters observed in the Washington system.

Table A.1. continued.

\begin{tabular}{|c|c|c|c|c|c|}
\hline Star cluster ${ }^{a}$ & $\begin{array}{c}\alpha_{2000} \\
(\mathrm{hms})\end{array}$ & $\begin{array}{c}\delta_{2000} \\
(\mathrm{dms})\end{array}$ & $\begin{array}{c}l \\
(\mathrm{deg})\end{array}$ & $\begin{array}{c}b \\
(\mathrm{deg})\end{array}$ & $\begin{array}{c}r^{b} \\
(\operatorname{arcmin})\end{array}$ \\
\hline SL 490, LW 217, KMHK 939 & 052718 & -734048 & 284.951 & -31.828 & 0.58 \\
\hline H 14, SL 506, LW 220, KMHK 967 & 052839 & -733749 & 284.871 & -31.745 & 0.70 \\
\hline SL 505, KMHK 960 & 052850 & -713758 & 282.560 & -32.120 & 0.58 \\
\hline SL 510, KMHK 968 & 052920 & -703446 & 281.325 & -32.262 & 0.36 \\
\hline KMHK 979, GKK-O101 & 052939 & -705902 & 281.790 & -32.168 & 0.30 \\
\hline HS 329, KMHK 984 & 052946 & -710002 & 281.807 & -32.156 & 0.35 \\
\hline SL 509, LW 221, ESO 85-91, KMHK 957 & 052948 & -633858 & 273.152 & -33.118 & 0.93 \\
\hline LW 224 & 052956 & -720317 & 283.030 & -31.959 & 0.21 \\
\hline КМHK 975 & 052959 & -675244 & 278.151 & -32.618 & 0.19 \\
\hline LW 231, KMHK 1031 & 053026 & -752057 & 286.813 & -31.270 & 0.45 \\
\hline LW 231, KMHK 1031 & 053026 & -752054 & 286.813 & -31.270 & 0.45 \\
\hline NGC 1997, SL 520, LW 226, ESO 86-1, KMHK 978 & 053034 & -631212 & 272.612 & -33.071 & 0.90 \\
\hline КМHК 993 & 053034 & -680927 & 278.469 & -32.526 & 0.28 \\
\hline SL 548, LW 235, KMHK 1035 & 053124 & -720233 & 282.990 & -31.848 & 0.33 \\
\hline SL 555, LW 236, KMHK 1046 & 053142 & -720846 & 283.108 & -31.805 & 0.70 \\
\hline KMHK 1023 & 053146 & -681408 & 278.544 & -32.405 & 0.31 \\
\hline SL 551,RHT 38a, KMHK1027, GKK-O202 & 053151 & -675928 & 278.255 & -32.429 & 0.49 \\
\hline KMHK 1029 & 053157 & -675243 & 278.122 & -32.435 & 0.31 \\
\hline BRHT 38b, KMHK 1032 & 053158 & -675818 & 278.228 & -32.420 & 0.35 \\
\hline SL549, KMHK1013 & 053203 & -641432 & 273.828 & -32.819 & 0.70 \\
\hline KMHK 1045 & 053223 & -675949 & 278.255 & -32.379 & 0.30 \\
\hline KMHK 1055 & 053302 & -675056 & 278.072 & -32.337 & 0.40 \\
\hline H 3, SL 569, KMHK 1065 & 053320 & -680908 & 278.424 & -32.272 & 0.90 \\
\hline IC 2140, SL 581, LW 241, ESO 33-24, KMHK 1106 & 053321 & -752235 & 286.800 & -31.084 & 1.15 \\
\hline SL 579, KMHK 1085 & 053413 & -675123 & 278.066 & -32.224 & 0.48 \\
\hline SL 588, KMHK 1101 & 053439 & -681820 & 278.587 & -32.129 & 0.68 \\
\hline IC 2146, SL 632, LW 258, ESO 33-26, KMHK 1178 & 053746 & -744658 & 286.058 & -30.917 & 1.65 \\
\hline LW 263, KMHK 1208 & 053908 & -745112 & 286.120 & -30.817 & 0.48 \\
\hline H88-306 & 054024 & -691510 & 279.623 & -31.505 & 0.28 \\
\hline H88-313 & 054121 & -690346 & 279.391 & -31.441 & 0.20 \\
\hline HS 390,MHK1239 & 054130 & -691106 & 279.532 & -31.416 & 0.33 \\
\hline H88-315, GKK-O164 & 054138 & -691848 & 279.680 & -31.391 & 0.25 \\
\hline NGC 2093, SL 657, ESO 56-23 & 054149 & -685515 & 279.221 & -31.414 & 0.70 \\
\hline H88-320,MHK 1248 & 054158 & -690251 & 279.365 & -31.388 & 0.30 \\
\hline H88-321 & 054208 & -692200 & 279.737 & -31.341 & 0.19 \\
\hline SL 663, LW 273, ESO 86-22, KMHK 1250 & 054229 & -652146 & 275.053 & -31.629 & 0.95 \\
\hline $\mathrm{H} 88-325$ & 054315 & -690203 & 279.337 & -31.275 & 0.23 \\
\hline SL 674, ESO 86-26, KMHK 1281 & 054320 & -661544 & 276.100 & -31.487 & 0.80 \\
\hline H88-326 & 054329 & -690944 & 279.484 & -31.242 & 0.24 \\
\hline SL 678, KMHK1283 & 054335 & -661231 & 276.034 & -31.464 & 0.58 \\
\hline H88-327, КМHК1295 & 054338 & -691551 & 279.603 & -31.219 & 0.35 \\
\hline H88-329, КМНК1297 & 054343 & -691323 & 279.554 & -31.216 & 0.29 \\
\hline NGC 2108, SL 686, ESO 57-33, KMHK 1304 & 054356 & -691050 & 279.503 & -31.200 & 0.90 \\
\hline H88-331,MHK1313 & 054411 & -692000 & 279.677 & -31.165 & 0.31 \\
\hline SL 691, BRHT 40a, KMHK 1319 & 054414 & -703920 & 281.213 & -31.027 & 0.38 \\
\hline SL 692, BRHT 40b, KMHK 1320 & 054415 & -704010 & 281.229 & -31.025 & 0.48 \\
\hline BSDL 2938, LOGLE 717 & 054442 & -702531 & 280.941 & -31.013 & 0.23 \\
\hline HS 406, KMHK 1332, LOGLE 720 & 054447 & -702422 & 280.917 & -31.008 & 0.33 \\
\hline HS 409, KMHK 1336, LOGLE 721 & 054457 & -701959 & 280.831 & -31.001 & 0.28 \\
\hline BSDL 2950, LOGLE 723 & 054501 & -703234 & 281.074 & -30.974 & 0.23 \\
\hline BSDL 2963, LOGLE 727 & 054520 & -703606 & 281.139 & -30.941 & 0.23 \\
\hline SL 704, KMHK 1343, LOGLE 728 & 054525 & -702405 & 280.905 & -30.955 & 0.39 \\
\hline H88-333 & 054527 & -692043 & 279.679 & -31.052 & 0.26 \\
\hline HS 410, KMHK 1344, LOGLE 729 & 054532 & -704534 & 281.320 & -30.910 & 0.36 \\
\hline BSDL 2972, LOGLE 731 & 054546 & -704309 & 281.271 & -30.894 & 0.24 \\
\hline HS411,MHK1345 & 054550 & -692249 & 279.716 & -31.016 & 0.23 \\
\hline HS412,MHK1347 & 054556 & -691619 & 279.589 & -31.016 & 0.35 \\
\hline
\end{tabular}


Table A.1. continued.

\begin{tabular}{|c|c|c|c|c|c|}
\hline Star cluster ${ }^{a}$ & $\begin{array}{c}\alpha_{2000} \\
(\mathrm{hms})\end{array}$ & $\begin{array}{c}\delta_{2000} \\
(\mathrm{dms})\end{array}$ & $\begin{array}{c}l \\
(\mathrm{deg})\end{array}$ & $\begin{array}{c}b \\
(\mathrm{deg})\end{array}$ & $\begin{array}{c}r^{b} \\
(\operatorname{arcmin})\end{array}$ \\
\hline BSDL 2978, LOGLE 732 & 054559 & -704346 & 281.281 & -30.876 & 0.20 \\
\hline LOGLE 733 & 054611 & -704312 & 281.268 & -30.860 & 0.17 \\
\hline SL 707, KMHK 1353 & 054612 & -690457 & 279.366 & -31.008 & 0.65 \\
\hline BSDL 2993, LOGLE 735 & 054637 & -704633 & 281.329 & -30.820 & 0.24 \\
\hline HS 414, BRHT 42b, KMHK 1365 & 054641 & -705052 & 281.411 & -30.807 & 0.44 \\
\hline SL 716, BRHT 42a, KMHK 1367 & 054647 & -704958 & 281.393 & -30.800 & 0.53 \\
\hline BSDL 3001, LOGLE 738 & 054648 & -703521 & 281.111 & -30.823 & 0.40 \\
\hline BSDL 2995 & 054651 & -692511 & 279.754 & -30.923 & 0.23 \\
\hline BSDL 3000, LOGLE 739 & 054651 & -703040 & 281.019 & -30.825 & 0.24 \\
\hline BSDL 3003, LOGLE 740 & 054652 & -704821 & 281.361 & -30.796 & 0.23 \\
\hline H88-334, КMHK 1363 & 054652 & -691123 & 279.486 & -30.940 & 0.36 \\
\hline BSDL 3050 & 054800 & -702830 & 280.968 & -30.734 & 0.34 \\
\hline KMHK 1389 & 054812 & -702800 & 280.956 & -30.718 & 0.38 \\
\hline BSDL 3060 & 054812 & -703324 & 281.061 & -30.710 & 0.37 \\
\hline HS 420, KMHK 1403 & 054828 & -703252 & 281.049 & -30.688 & 0.34 \\
\hline BSDL 3072 & 054833 & -702900 & 280.973 & -30.687 & 0.40 \\
\hline BSDL 3071 & 054835 & -701839 & 280.773 & -30.699 & 0.20 \\
\hline KMHK 1408 & 054846 & -702823 & 280.959 & -30.670 & 0.55 \\
\hline SL 736 & 054917 & -704754 & 281.331 & -30.599 & 0.36 \\
\hline HS 424, KMHK 1425 & 054936 & -704135 & 281.207 & -30.582 & 0.39 \\
\hline H 7, SL 735, ESO 57-43,BM 109 & 055003 & -674305 & 277.753 & -30.746 & 1.15 \\
\hline SL 748, KMHK 1437 & 055015 & -702540 & 280.895 & -30.550 & 0.60 \\
\hline HS 427, КMHK 1443 & 055017 & -703656 & 281.111 & -30.532 & 0.43 \\
\hline КMHK 1448 & 055028 & -703233 & 281.027 & -30.523 & 0.34 \\
\hline BSDL 3123 & 055045 & -703434 & 281.063 & -30.497 & 0.23 \\
\hline C 11 & 055048 & -714228 & 282.371 & -30.397 & 0.20 \\
\hline BSDL 3158 & 055211 & -715130 & 282.533 & -30.276 & 0.46 \\
\hline KMHK 1504 & 055315 & -715332 & 282.563 & -30.191 & 0.32 \\
\hline SL 769, KMHK1499 & 055323 & -700416 & 280.459 & -30.310 & 0.90 \\
\hline H88-365, КМHK 1507 & 055327 & -714110 & 282.325 & -30.192 & 0.34 \\
\hline SL 775, LW 327, KMHK 1506 & 055327 & -714257 & 282.359 & -30.189 & 0.60 \\
\hline OHSC 28 & 055535 & -622043 & 271.508 & -30.237 & 0.35 \\
\hline NGC 2161, SL 789, LW 337, ESO 33-31, KMHK 1544 & 055542 & -742114 & 285.376 & -29.793 & 1.15 \\
\hline NGC 2153, SL 792, LW 341, ESO 86-43, KMHK 1555 & 055751 & -662402 & 276.200 & -30.025 & 0.75 \\
\hline NGC 2155, SL 803, LW 347, ESO 86-45, KMHK 1563 & 055833 & -652837 & 275.134 & -29.958 & 1.20 \\
\hline SL 817, KMHK 1588 & 060038 & -700410 & 280.425 & -29.695 & 0.70 \\
\hline SL 826, LW 363, KMHK,1606 & 060152 & -722119 & 283.046 & -29.500 & 0.75 \\
\hline ESO 121-03, KMHK 1591 & 060202 & -603124 & 269.451 & -29.382 & 1.05 \\
\hline LW 393, КMHK 1648 & 060631 & -721335 & 282.882 & -29.151 & 0.26 \\
\hline LW 397, KMHK 1657 & 060729 & -722939 & 283.187 & -29.071 & 0.34 \\
\hline SL 842, LW 399, ESO 86-61, KMHK 1652 & 060815 & -625915 & 272.323 & -28.814 & 0.85 \\
\hline KMHK 1668 & 060853 & -722302 & 283.056 & -28.968 & 0.29 \\
\hline NGC 2213, SL 857, LW 419, ESO 57-70, KMHK 1681 & 061042 & 713144 & 282.078 & -28.839 & 1.05 \\
\hline SL 862, LW 431, ESO 57-75, KMHK 1692 & 061327 & -704145 & 281.128 & -28.613 & 0.85 \\
\hline SL 870, LW 440, KMHK 1705 & 061428 & -723634 & 283.310 & -28.546 & 0.58 \\
\hline SL 869, LW 341, KMHK 1704 & 061441 & -694807 & 280.114 & -28.490 & 0.80 \\
\hline KMHK 1702 & 061454 & -723019 & 283.190 & -28.586 & 0.31 \\
\hline OHSC 33, KMHK 1714 & 061517 & -734707 & 284.647 & -28.482 & 0.20 \\
\hline SL 874, LW 446, ESO 57-77, KMHK 1713 & 061557 & -700423 & 280.426 & -28.390 & 0.75 \\
\hline КMHK 1719 & 061719 & -700339 & 280.417 & -28.273 & 0.44 \\
\hline LW 469, KMHK 1742 & 062134 & -724724 & 283.522 & -28.021 & 0.53 \\
\hline SL 896, LW 480, KMHK 1758 & 062958 & -692001 & 279.677 & -27.131 & 0.50 \\
\hline OHSC 37, KMHK 1762 & 070739 & -695902 & 280.983 & -24.011 & 0.29 \\
\hline
\end{tabular}


T. Palma et al.: Catalogue of LMC star clusters observed in the Washington system.

Table A.2. Fundamental parameters for the star cluster sample.

\begin{tabular}{|c|c|c|c|c|c|c|c|c|c|}
\hline ID & $\begin{array}{l}\text { Radius } \\
\text { (arcmin) }\end{array}$ & $\begin{array}{l}\text { Deproj. } \\
\text { dist (deg) }\end{array}$ & $E(B-V)$ & $\begin{array}{l}\mathrm{Age}_{\mathrm{I}} \\
(\mathrm{Gyr})\end{array}$ & $\begin{array}{c}{[\mathrm{Fe} / \mathrm{H}]_{\mathrm{I}}} \\
(\mathrm{dex})\end{array}$ & $\begin{array}{c}\text { Age }_{\text {II }} \\
( \pm 0.30 \mathrm{Gyr})\end{array}$ & $\begin{array}{c}{[\mathrm{Fe} / \mathrm{H}]_{\mathrm{II}}} \\
( \pm 0.3 \mathrm{dex})\end{array}$ & Notes & Ref. \\
\hline HS 8 & $\ldots$ & 6.2 & 0.026 & $\ldots$ & $\ldots$ & 1.60 & $\ldots$ & $\ldots$ & 1 \\
\hline SL 5 & $\ldots$ & 6.8 & 0.082 & $\ldots$ & $\ldots$ & 2.50 & $\ldots$ & $\ldots$ & 1 \\
\hline NGC 1644 & $\ldots$ & 6.3 & 0.018 & $\ldots$ & $\ldots$ & 2.50 & & $\ldots$ & 1 \\
\hline SL 8 & $\ldots$ & 4.2 & 0.040 & $\ldots$ & $\ldots$ & $1.60 / 1.80$ & -0.50 & $\mathrm{a}$ & 2,3 \\
\hline SL 13 & $\ldots$ & 6.8 & 0.049 & $\ldots$ & $\ldots$ & 2.50 & $\ldots$ & $\ldots$ & 1 \\
\hline КМНК 58 & $\ldots$ & 6.5 & 0.089 & $\ldots$ & $\ldots$ & 1.60 & $\ldots$ & $\ldots$ & 1 \\
\hline LW 54 & 0.30 & 5.0 & 0.000 & $0.40 \pm 0.08$ & -0.40 & $\ldots$ & $\ldots$ & $\mathrm{a}$ & 4 \\
\hline SL 33 & 0.90 & 5.1 & 0.116 & $2.20_{-0.2}^{+0.3}$ & -0.40 & & -0.60 & $\mathrm{~m} 1$ & 5,17 \\
\hline SL 35 & $\ldots$ & 4.3 & 0.051 & $\ldots$ & $\ldots$ & 1.50 & $\ldots$ & $\mathrm{a}$ & 1 \\
\hline КМНК 95 & 0.35 & 4.2 & 0.041 & $0.35 \pm 0.07$ & -0.40 & $\ldots$ & $\ldots$ & $\ldots$ & 4 \\
\hline SL 41 & 0.99 & 5.1 & 0.116 & $1.58 \pm 0.20$ & -0.57 & 1.40 & $\ldots$ & $\ldots$ & 5,17 \\
\hline NGC 1697 & 1.67 & 3.5 & 0.040 & $0.70 \pm 0.10$ & 0.00 & $\ldots$ & $\ldots$ & $\ldots$ & 6 \\
\hline KMHK 123 & 0.50 & 5.0 & 0.118 & $1.12 \pm 0.10$ & -0.54 & $\ldots$ & $\ldots$ & $\ldots$ & 5,17 \\
\hline KMHK 112 & & 4.4 & 0.048 & & & 1.25 & & $\mathrm{a}$ & 1 \\
\hline КМHK 128 & 0.50 & 5.4 & 0.111 & $1.60 \pm 0.20$ & -0.84 & & -0.90 & $\ldots$ & 5,17 \\
\hline SL 48 & 0.90 & 5.1 & 0.118 & $2.50 \pm 0.30$ & -0.72 & 2.10 & -0.80 & $\ldots$ & 7 \\
\hline LW 69 & 0.54 & 4.6 & 0.122 & $1.80 \pm 0.20$ & -0.72 & 1.70 & $\ldots$ & $\ldots$ & 5,17 \\
\hline KMHK 151 & 0.77 & 5.1 & 0.118 & $1.40 \pm 0.20$ & -0.72 & 1.40 & -0.80 & $\ldots$ & 5,17 \\
\hline BSDL 77 & 0.40 & 4.3 & 0.000 & $0.79 \pm 0.16$ & -0.40 & $\ldots$ & $\ldots$ & $\ldots$ & 4 \\
\hline SL 54 & 0.90 & 4.9 & 0.120 & $1.00 \pm 0.10$ & -0.47 & $\ldots$ & $\ldots$ & $\ldots$ & 5,17 \\
\hline BSDL 87 & 0.18 & 4.0 & 0.050 & $0.08 \pm 0.01$ & -0.40 & $\ldots$ & $\ldots$ & $\mathrm{b}$ & 8 \\
\hline HS 38 & 0.25 & 4.0 & 0.050 & $0.40 \pm 0.10$ & -0.40 & $\ldots$ & $\ldots$ & $a, b$ & 9 \\
\hline HS 41 & 0.18 & 4.1 & 0.048 & $0.06 \pm 0.01$ & -0.40 & $\ldots$ & $\ldots$ & $\mathrm{a}$ & 8 \\
\hline КMHK 183 & 0.72 & 4.5 & 0.122 & $0.79 \pm 0.09$ & -0.40 & $\ldots$ & $\ldots$ & $\mathrm{a}$ & 9 \\
\hline SL 73 & 0.86 & 4.7 & 0.120 & $1.78 \pm 0.20$ & -0.70 & 1.60 & -0.80 & $\ldots$ & 5,17 \\
\hline SL 72 & 0.72 & 4.4 & 0.133 & $0.28 \pm 0.03$ & -0.40 & $\ldots$ & $\ldots$ & $\ldots$ & 5,17 \\
\hline КМHK 229 & 0.25 & 2.6 & 0.100 & $1.00 \pm 0.20$ & -0.40 & $\ldots$ & $\ldots$ & $a, b$ & 9 \\
\hline BSDL 192 & 0.18 & 2.6 & 0.102 & $0.10 \pm 0.01$ & -0.40 & $\ldots$ & $\ldots$ & $\mathrm{m} 2 / \mathrm{a}, \mathrm{b}$ & 8 \\
\hline BSDL 194 & 0.14 & 2.6 & 0.102 & $0.25 \pm 0.03$ & -0.40 & $\ldots$ & $\ldots$ & b & 8 \\
\hline NGC 1751 & $\ldots$ & 2.6 & 0.102 & $\ldots$ & $\ldots$ & 1.30 & $\ldots$ & $\ldots$ & 1 \\
\hline SL96 & $\ldots$ & 3.6 & 0.058 & & $\ldots$ & 1.60 & $\ldots$ & $\ldots$ & 1 \\
\hline H88-26 & 0.33 & 3.3 & 0.060 & $0.80 \pm 0.20$ & -0.40 & $\ldots$ & $\ldots$ & $\mathrm{b}$ & 9 \\
\hline H88-32 & 0.14 & 3.5 & 0.058 & $0.25 \pm 0.03$ & -0.40 & $\ldots$ & $\ldots$ & b & 8 \\
\hline H88-34 & 0.14 & 3.1 & 0.058 & $0.25 \pm 0.03$ & -0.40 & $\ldots$ & $\ldots$ & b & 8 \\
\hline H88-33 & 0.30 & 3.4 & 0.066 & $0.16-0.32 \pm 0.20$ & -0.40 & $\ldots$ & $\ldots$ & $\mathrm{b}$ & 4 \\
\hline BSDL 268 & 0.99 & 2.5 & 0.102 & $0.09 \pm 0.02$ & -0.40 & $\ldots$ & $\ldots$ & $\mathrm{a}, \mathrm{b}$ & 4 \\
\hline BRHT 60b & 0.14 & 3.2 & 0.060 & $0.08 \pm 0.01$ & -0.40 & $\ldots$ & $\ldots$ & $\mathrm{m} 3 / \mathrm{a}, \mathrm{b}$ & 8 \\
\hline NGC 1764 & 0.23 & 3.5 & 0.058 & $0.08 \pm 0.01$ & -0.40 & $\ldots$ & $\ldots$ & $a, b$ & 8 \\
\hline H88-40 & 0.33 & 3.5 & 0.060 & $0.70 \pm 0.20$ & -0.40 & $\ldots$ & $\ldots$ & $\mathrm{b}$ & 9 \\
\hline SL 124w & 0.14 & 2.5 & 0.115 & $0.50 \pm 0.05$ & -0.40 & $\ldots$ & $\ldots$ & $\mathrm{m} 4$ & 8 \\
\hline SL $124 \mathrm{e}$ & 0.14 & 2.5 & 0.115 & $0.50 \pm 0.05$ & -0.40 & $\ldots$ & $\ldots$ & $\mathrm{m} 4 / \mathrm{b}$ & 8 \\
\hline КMHK 335 & 0.09 & 2.5 & 0.115 & $0.10 \pm 0.01$ & -0.40 & $\ldots$ & $\ldots$ & $\mathrm{b}$ & 8 \\
\hline BRHT $45 b$ & 0.14 & 3.2 & 0.060 & $0.08 \pm 0.01$ & -0.40 & $\ldots$ & $\ldots$ & $\mathrm{m} 5 / \mathrm{a}, \mathrm{b}$ & 8 \\
\hline BRHT 45a & 0.45 & 3.2 & 0.076 & $0.13 \pm 0.03$ & -0.40 & $\ldots$ & $\ldots$ & $\mathrm{m} 5 / \mathrm{a}, \mathrm{b}$ & 4 \\
\hline BSDL 320 & 0.14 & 2.5 & 0.115 & $0.10 \pm 0.01$ & -0.40 & & $\ldots$ & $a, b$ & 8 \\
\hline SL 126 & $\ldots$ & 8.9 & 0.000 & $\ldots$ & $\ldots$ & $2.50 / 2.20$ & -0.45 & $\ldots$ & 2,3 \\
\hline SL 132 & $\ldots$ & 3.4 & 0.057 & $\ldots$ & $\ldots$ & 1.60 & $\ldots$ & $\mathrm{a}$ & 1 \\
\hline SL 133 & 1.13 & 5.9 & 0.020 & $2.00 \pm 0.20$ & -0.70 & 2.30 & $\ldots$ & & 6 \\
\hline H88-52 & 0.45 & 3.0 & 0.041 & $1.12 \pm 0.23$ & -0.40 & 1.40 & $\ldots$ & $\mathrm{m} 6 / \mathrm{b}$ & 1,4 \\
\hline H88-55 & 0.33 & 3.3 & 0.060 & $0.50 \pm 0.10$ & -0.40 & $\ldots$ & $\ldots$ & $\mathrm{b}$ & 9 \\
\hline BSDL 341 & 0.40 & 3.0 & 0.086 & $0.28 \pm 0.06$ & -0.40 & & $\ldots$ & $\mathrm{m} 6 / \mathrm{b}$ & 4 \\
\hline SL 151 & $\ldots$ & 2.3 & 0.102 & $\ldots$ & $\ldots$ & 1.50 & $\ldots$ & $\ldots$ & 1 \\
\hline H88-67 & $\ldots$ & 3.1 & 0.062 & $\ldots$ & $\ldots$ & 1.70 & $\ldots$ & $\ldots$ & 1 \\
\hline SL 154 & 0.33 & 3.0 & 0.060 & $0.50 \pm 0.10$ & -0.40 & $\ldots$ & $\ldots$ & $\mathrm{b}$ & 9 \\
\hline NGC 1793 & 0.42 & 2.1 & 0.107 & $0.11 \pm 0.02$ & -0.40 & $\ldots$ & $\ldots$ & $a, b$ & 4 \\
\hline NGC 1795 & $\ldots$ & 2.1 & 0.096 & $\ldots$ & $\ldots$ & 1.60 & $\ldots$ & $\ldots$ & 1 \\
\hline SL 162 & $\ldots$ & 3.0 & 0.062 & . & $\ldots$ & 1.50 & $\ldots$ & $\mathrm{a}$ & 1 \\
\hline BRHT 62a & 0.32 & 3.1 & 0.062 & $0.16 \pm 0.02$ & -0.40 & $\ldots$ & $\ldots$ & $a, b$ & 8 \\
\hline КМHК 506 & 0.17 & 2.2 & 0.060 & $0.56 \pm 0.07$ & -0.40 & $\ldots$ & $\ldots$ & $\ldots$ & 9 \\
\hline
\end{tabular}

Notes. Parameters obtained also by (a) Glatt et al. (2010), (b) Popescu et al. (2012), and (c) Pietrzyński \& Udalski (2000). The letter m indicates that the cluster belongs to a binary or multple system.

References. 1) Piatti (2011); 2) Geisler et al. (1997); 3) Bica et al. (1998); 4) Choudhury et al. (2015); 5) Palma et al. (2013); 6) Piatti et al. (2009b); 7) Palma et al. (2015); 8) Piatti (2014); 9) Piatti (2012); 10) Piatti et al. (2003b); 11) Piatti et al. (2003a); 12) Geisler et al. (2003); 13) Palma et al. (2011); 14) Piatti et al. (2011); 15) Piatti et al. (2002); 16) Geisler (1987); 17) present work. 
Table A.2. continued.

\begin{tabular}{|c|c|c|c|c|c|c|c|c|c|}
\hline ID & $\begin{array}{l}\text { Radius } \\
\text { (arcmin) }\end{array}$ & $\begin{array}{c}\text { Deproj. } \\
\text { dist (deg) }\end{array}$ & $E(B-V)$ & $\begin{array}{l}\mathrm{Age}_{\mathrm{I}} \\
(\mathrm{Gyr})\end{array}$ & $\begin{array}{c}{[\mathrm{Fe} / \mathrm{H}]_{\mathrm{I}}} \\
(\operatorname{dex})\end{array}$ & $\begin{array}{c}\text { Age }_{\text {II }} \\
( \pm 0.30 \mathrm{Gyr})\end{array}$ & $\begin{array}{c}{[\mathrm{Fe} / \mathrm{H}]_{\mathrm{II}}} \\
( \pm 0.3 \mathrm{dex})\end{array}$ & Notes & Ref. \\
\hline BSDL 527 & $\ldots$ & 2.4 & 0.059 & 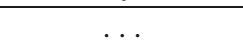 & $\ldots$ & 1.40 & $\ldots$ & $\ldots$ & 1 \\
\hline SL 218 & $\ldots$ & 2.0 & 0.060 & $0.05 \pm 0.01$ & -0.40 & $\ldots$ & $\ldots$ & $\mathrm{a}, \mathrm{b}, \mathrm{c}$ & 10 \\
\hline NGC 1836 & $\ldots$ & 1.9 & 0.060 & $0.40 \pm 0.10$ & 0.00 & $\ldots$ & $\ldots$ & $\mathrm{m} 7 / \mathrm{b}$ & 11 \\
\hline BRHT 4b & $\ldots$ & 1.9 & 0.060 & $0.10 \pm 0.02$ & -0.40 & $\ldots$ & $\ldots$ & $\mathrm{m} 7 / \mathrm{a}, \mathrm{c}$ & 10 \\
\hline BSDL 594 & 0.63 & 3.4 & 0.046 & $1.58_{-0.17}^{+0.20}$ & -0.47 & 1.30 & $\ldots$ & $\mathrm{c}$ & 5,17 \\
\hline HS 113 & 0.23 & 2.2 & 0.059 & $0.20 \pm 0.02$ & -0.40 & $\ldots$ & $\ldots$ & $\mathrm{m} 8$ & 8 \\
\hline NGC 1839 & $\ldots$ & 1.9 & 0.060 & $0.13 \pm 0.02$ & -0.40 & $\ldots$ & $\ldots$ & $a, b$ & 10 \\
\hline HS 114 & $\ldots$ & 2.4 & 0.055 & $\ldots$ & $\ldots$ & 1.30 & $\ldots$ & $\ldots$ & 1 \\
\hline NGC 1838 & $\ldots$ & 2.0 & 0.060 & $0.10 \pm 0.02$ & -0.40 & $\ldots$ & $\ldots$ & $\mathrm{a}$ & 10 \\
\hline HS 116 & 0.30 & 2.4 & 0.041 & $0.35 \pm 0.07$ & -0.40 & $\ldots$ & $\ldots$ & $\ldots$ & 4 \\
\hline SL 229 & 0.33 & 2.1 & 0.060 & $0.32 \pm 0.10$ & -0.40 & $\ldots$ & -0.40 & $\mathrm{~m} 9 / \mathrm{c}$ & 4,9 \\
\hline SL 230 & 0.42 & 2.1 & 0.081 & $0.08 \pm 0.02$ & -0.40 & $\ldots$ & $\ldots$ & $\mathrm{m} 9 / \mathrm{a}$ & 4 \\
\hline BSDL 631 & 0.25 & 2.0 & 0.000 & $0.22 \pm 0.05$ & -0.40 & $\ldots$ & $\ldots$ & $\mathrm{a}, \mathrm{c}$ & 4 \\
\hline H88-131 & 0.40 & 2.6 & 0.030 & $1.00 \pm 0.21$ & -0.40 & $\ldots$ & $\ldots$ & $\ldots$ & 4 \\
\hline OGLE 122 & 0.18 & 2.0 & 0.059 & $0.40 \pm 0.04$ & -0.40 & $\ldots$ & $\ldots$ & $\mathrm{c}$ & 8 \\
\hline BSDL 654 & 0.34 & 3.6 & 0.033 & $0.22 \pm 0.03$ & -0.02 & $\ldots$ & $\ldots$ & $\mathrm{c}$ & 5,17 \\
\hline LOGLE 127 & 0.23 & 2.8 & 0.061 & $0.10 \pm 0.01$ & -0.40 & $\ldots$ & $\ldots$ & $\mathrm{c}$ & 8 \\
\hline NGC 1846 & $\ldots$ & 2.9 & 0.061 & $\ldots$ & $\ldots$ & 1.40 & $\ldots$ & $\ldots$ & 1 \\
\hline SL 244 & $\ldots$ & 1.8 & 0.060 & $\ldots$ & $\ldots$ & $1.60 / 1.30$ & -0.30 & $\mathrm{~b}$ & 2,12 \\
\hline HS 121 & $\ldots$ & 2.5 & 0.060 & $\ldots$ & $\ldots$ & 1.50 & $\ldots$ & $\ldots$ & 1 \\
\hline BDSL 665 & 0.27 & 3.6 & 0.033 & $0.90 \pm 0.10$ & -0.41 & $\ldots$ & $\ldots$ & $\mathrm{c}$ & 5,17 \\
\hline BSDL 675 & 0.41 & 3.0 & 0.061 & $1.40 \pm 0.20$ & -0.40 & 1.40 & $\ldots$ & $\mathrm{c}$ & 5,17 \\
\hline KMHK 575 & 0.59 & 4.2 & 0.043 & $0.89_{-0.19}^{+0.23}$ & $\ldots$ & $\ldots$ & $\ldots$ & $\mathrm{c}$ & 7 \\
\hline КМHK 586 & $\ldots$ & 2.3 & 0.055 & $\ldots$ & $\ldots$ & 1.80 & $\ldots$ & $\ldots$ & 1 \\
\hline BSDL 716 & 0.50 & 2.2 & 0.060 & $0.40 \pm 0.10$ & -0.40 & $\ldots$ & $\ldots$ & $\ldots$ & 9 \\
\hline SL 263 & 0.45 & 3.6 & 0.043 & $0.02_{-0.005}^{+0.006}$ & -0.23 & $\ldots$ & $\ldots$ & $\mathrm{c}$ & 7 \\
\hline GKK-O222 & 0.14 & 2.3 & 0.055 & $1.58 \pm 0.16$ & -0.40 & $\ldots$ & $\ldots$ & $\ldots$ & 8 \\
\hline HS 131 & 0.45 & 1.8 & 0.081 & $1.26 \pm 0.26$ & -0.40 & $\ldots$ & $\ldots$ & $\ldots$ & 4 \\
\hline HS 130 & 0.41 & 2.5 & 0.061 & $0.16 \pm 0.02$ & -0.41 & $\ldots$ & $\ldots$ & $\ldots$ & 5,17 \\
\hline SL 262 & $\ldots$ & 8.6 & 0.001 & $\ldots$ & $\ldots$ & 2.10 & -0.55 & $\ldots$ & 2,3 \\
\hline NGC 1852 & $\ldots$ & 2.5 & 0.060 & $\ldots$ & $\ldots$ & 1.40 & $\ldots$ & $\ldots$ & 1 \\
\hline BSDL 761 & 0.41 & 3.6 & 0.036 & $0.16 \pm 0.02$ & -0.40 & $\ldots$ & $\ldots$ & $\ldots$ & 5,17 \\
\hline GKK-O220 & 0.23 & 2.3 & 0.060 & $0.79 \pm 0.08$ & -0.40 & $\ldots$ & $\ldots$ & $\ldots$ & 8 \\
\hline HS 151 & 0.33 & 1.8 & 0.060 & $0.79 \pm 0.10$ & -0.40 & $\ldots$ & $\ldots$ & $\ldots$ & 9 \\
\hline BSDL 779 & 0.36 & 3.3 & 0.043 & $0.10 \pm 0.01$ & -0.02 & $\ldots$ & $\ldots$ & $\mathrm{c}$ & 5,17 \\
\hline SL 281 & 0.95 & 3.1 & 0.052 & $0.05_{-0.005}^{+0.006}$ & -0.31 & $\ldots$ & $\ldots$ & $\mathrm{a}, \mathrm{c}$ & 17 \\
\hline SL 290 & $\ldots$ & 1.7 & 0.101 & $\ldots$ & $\ldots$ & 1.20 & $\ldots$ & $\mathrm{a}$ & 1 \\
\hline BSDL 783 & 0.32 & 3.6 & 0.072 & $0.16 \pm 0.01$ & -0.30 & $\ldots$ & $\ldots$ & $\mathrm{a}, \mathrm{c}$ & 17 \\
\hline NGC 1860 & $\ldots$ & 1.4 & 0.080 & $0.25 \pm 0.50$ & 0.00 & $\ldots$ & $\ldots$ & $\mathrm{b}, \mathrm{c}$ & 11 \\
\hline BSDL 794 & 0.45 & 2.7 & 0.060 & $0.80_{-0.17}^{+0.3}$ & -0.41 & $\ldots$ & $\ldots$ & $\mathrm{m} 10$ & 7 \\
\hline H88-188 & 0.41 & 2.7 & 0.061 & $0.63_{-0.07}^{+0.08}$ & -0.27 & $\ldots$ & $\ldots$ & $\mathrm{m} 10 / \mathrm{c}$ & 9,17 \\
\hline HS 154 & 0.33 & 2.5 & 0.060 & $0.45-0.50 \pm 0.10$ & -0.40 & $\ldots$ & $\ldots$ & $\mathrm{m} 11 / \mathrm{c}$ & 4,9 \\
\hline SL 293 & $0.63 / 0.5$ & 2.5 & 0.061 & $0.40 \pm 0.05$ & -0.31 & $\ldots$ & $\ldots$ & $\ldots$ & 9,17 \\
\hline HS 156 & 0.54 & 2.5 & 0.061 & $1.25_{-0.1}^{+0.2}$ & $\begin{array}{l}0.40 \\
-0.47\end{array}$ & $\ldots$ & $\ldots$ & $\mathrm{m} 11 / \mathrm{c}$ & $4,5,8,17$ \\
\hline NGC 1863 & $\ldots$ & 1.4 & 0.060 & $0.04 \pm 0.01$ & -0.40 & $\ldots$ & $\ldots$ & $\mathrm{a}, \mathrm{b}, \mathrm{c}$ & 10 \\
\hline SL 300 & 0.67 & 2.6 & 0.060 & $0.40 \pm 0.10$ & -0.40 & $\ldots$ & $\ldots$ & $\mathrm{c}$ & 9 \\
\hline NGC 1865 & $\ldots$ & 1.3 & 0.060 & $0.50 \pm 0.10$ & -0.20 & $\ldots$ & $\ldots$ & $\mathrm{m} 12 / \mathrm{c}$ & 2,11 \\
\hline SL 310 & 0.68 & 2.8 & 0.061 & $0.05 \pm 0.01$ & -0.30 & $\ldots$ & $\ldots$ & $\mathrm{a}, \mathrm{c}$ & 17 \\
\hline NGC 1864 & 0.99 & 2.5 & 0.061 & $0.25 \pm 0.03$ & -0.40 & $\ldots$ & $\ldots$ & a & 17 \\
\hline BSDL 923 & 0.41 & 2.7 & 0.060 & $0.10_{-0.01}^{+0.02}$ & -0.36 & $\ldots$ & $\ldots$ & a & 17 \\
\hline HS 178 & 0.54 & 3.5 & 0.036 & $0.71 \pm 0.08$ & -0.41 & $\ldots$ & $\ldots$ & $\ldots$ & 5 \\
\hline NGC 1885 & 0.32 & 0.9 & 0.081 & $0.06 \pm 0.01$ & -0.40 & $\ldots$ & $\ldots$ & $\mathrm{c}$ & 8 \\
\hline BSDL 1024 & 1.00 & 1.0 & 0.080 & $0.16 \pm 0.03$ & -0.40 & $\ldots$ & $\ldots$ & $\mathrm{c}$ & 9 \\
\hline OGLE 264 & 0.18 & 0.7 & 0.078 & $0.63 \pm 0.06$ & -0.40 & $\ldots$ & $\ldots$ & $\mathrm{c}$ & 8 \\
\hline H88-232 & 0.18 & 0.8 & 0.078 & $0.13 \pm 0.01$ & -0.40 & $\ldots$ & $\ldots$ & $\mathrm{m} 13 / \mathrm{c}$ & 8 \\
\hline
\end{tabular}


T. Palma et al.: Catalogue of LMC star clusters observed in the Washington system.

Table A.2. continued.

\begin{tabular}{|c|c|c|c|c|c|c|c|c|c|}
\hline ID & $\begin{array}{l}\text { Radius } \\
\text { (arcmin) }\end{array}$ & $\begin{array}{c}\text { Deproj. } \\
\text { dist (deg) }\end{array}$ & $E(B-V)$ & $\begin{array}{l}\text { Age }_{\text {I }} \\
\text { (Gyr) }\end{array}$ & $\begin{array}{c}{[\mathrm{Fe} / \mathrm{H}]_{\mathrm{I}}} \\
(\mathrm{dex})\end{array}$ & $\begin{array}{c}\text { Age }_{\text {II }} \\
( \pm 0.30 \mathrm{Gyr})\end{array}$ & $\begin{array}{c}{[\mathrm{Fe} / \mathrm{H}]_{\mathrm{II}}} \\
( \pm 0.3 \mathrm{dex})\end{array}$ & Notes & Ref. \\
\hline BSDL 1035 & 0.17 & 1.2 & 0.060 & $0.50 \pm 0.10$ & -0.40 & $\ldots$ & $\ldots$ & & 9 \\
\hline HS 198 & 0.14 & 0.8 & 0.078 & $0.14 \pm 0.01$ & -0.40 & $\ldots$ & $\ldots$ & $\mathrm{m} 13 / \mathrm{b}, \mathrm{c}$ & 8 \\
\hline HS 200 & 0.18 & 0.7 & 0.086 & $0.50 \pm 0.05$ & -0.40 & $\ldots$ & $\ldots$ & $\mathrm{b}, \mathrm{c}$ & 8 \\
\hline OGLE 271 & 0.27 & 0.9 & 0.078 & $0.40 \pm 0.04$ & -0.40 & $\ldots$ & $\ldots$ & $\mathrm{c}$ & 8 \\
\hline H88-238 & 0.23 & 0.6 & 0.090 & $0.13 \pm 0.01$ & -0.40 & $\ldots$ & $\ldots$ & $\mathrm{b}, \mathrm{c}$ & 8 \\
\hline H88-240 & 0.27 & 0.7 & 0.081 & $0.20 \pm 0.02$ & -0.40 & $\ldots$ & $\ldots$ & $\mathrm{b}, \mathrm{c}$ & 8 \\
\hline H88-245 & 0.50 & 0.7 & 0.080 & $0.16 \pm 0.04$ & -0.40 & $\ldots$ & $\ldots$ & $\mathrm{b}, \mathrm{c}$ & 9 \\
\hline H88-249 & 0.14 & 0.6 & 0.090 & $0.32 \pm 0.03$ & -0.40 & $\ldots$ & $\ldots$ & $\ldots$ & 8 \\
\hline HS 205 & 0.27 & 0.8 & 0.081 & $0.10 \pm 0.01$ & -0.40 & $\ldots$ & $\ldots$ & $\mathrm{c}$ & 8 \\
\hline H88-252 & 0.23 & 0.6 & 0.090 & $0.25 \pm 0.03$ & -0.40 & $\ldots$ & & b & 8 \\
\hline H88-253 & 0.18 & 0.7 & 0.081 & $0.20 \pm 0.02$ & -0.40 & $\ldots$ & $\ldots$ & $\mathrm{m} 14 / \mathrm{c}$ & 8 \\
\hline OGLE 297 & 0.27 & 0.7 & 0.081 & $0.08 \pm 0.01$ & -0.40 & $\ldots$ & $\ldots$ & $\mathrm{b}, \mathrm{c}$ & 8 \\
\hline SL 351 & 0.33 & 1.1 & 0.060 & $0.50 \pm 0.10$ & -0.40 & $\ldots$ & $\ldots$ & $\ldots$ & 9 \\
\hline H88-259 & 0.18 & 0.6 & 0.081 & $0.79 \pm 0.08$ & -0.40 & $\ldots$ & $\ldots$ & $\mathrm{c}$ & 8 \\
\hline H88-260 & 0.18 & 0.5 & 0.090 & $0.40 \pm 0.04$ & -0.40 & $\ldots$ & $\ldots$ & $\mathrm{c}$ & 8 \\
\hline H88-261 & 0.32 & 0.6 & 0.081 & $0.50 \pm 0.05$ & -0.40 & $\ldots$ & $\ldots$ & $\mathrm{c}$ & 8 \\
\hline SL 359 & $\ldots$ & 1.3 & 0.060 & $\ldots$ & $\ldots$ & 1.60 & -0.4 & $\ldots$ & 2,12 \\
\hline H88-265 & 0.33 & 0.5 & 0.051 & $0.20 \pm 0.04$ & -0.40 & $\ldots$ & $\ldots$ & $\mathrm{b}, \mathrm{c}$ & 4 \\
\hline H88-269 & 0.33 & 0.5 & 0.051 & $0.79 \pm 0.16$ & -0.40 & $\ldots$ & $\ldots$ & $\mathrm{c}$ & 4 \\
\hline OGLE 340 & 0.36 & 0.4 & 0.090 & $0.04 \pm 0.00$ & -0.40 & $\ldots$ & $\ldots$ & $\mathrm{c}$ & 8 \\
\hline H88-270 & 0.18 & 0.3 & 0.090 & $1.26 \pm 0.13$ & -0.40 & $\ldots$ & $\ldots$ & $\mathrm{b}$ & 8 \\
\hline NGC 1917 & $\ldots$ & 0.6 & 0.081 & $\ldots$ & $\ldots$ & 1.30 & $\ldots$ & $\ldots$ & 1 \\
\hline H88-272 & 0.23 & 0.8 & 0.060 & $0.32 \pm 0.03$ & -0.40 & $\ldots$ & $\ldots$ & $\mathrm{m} 15$ & 8 \\
\hline OGLE 346 & 0.25 & 0.3 & 0.090 & $0.16 \pm 0.02$ & -0.40 & $\ldots$ & $\ldots$ & $\mathrm{c}$ & 8 \\
\hline HS 228 & 0.27 & 0.7 & 0.060 & $1.26 \pm 0.13$ & -0.40 & $\ldots$ & $\ldots$ & $\mathrm{m} 15 / \mathrm{b}$ & 8 \\
\hline SL 390 & 0.32 & 0.6 & 0.081 & $1.00 \pm 0.10$ & -0.40 & $\ldots$ & $\ldots$ & $\mathrm{b}, \mathrm{c}$ & 8 \\
\hline H88-276 & 0.23 & 0.8 & 0.060 & $0.79 \pm 0.08$ & -0.40 & $\ldots$ & $\ldots$ & $\mathrm{b}$ & 8 \\
\hline OGLE 363 & 0.18 & 0.3 & 0.090 & $0.10 \pm 0.01$ & -0.40 & $\ldots$ & $\ldots$ & $\mathrm{c}$ & 8 \\
\hline SL 388 & 0.50 & 7.0 & 0.030 & $\ldots$ & $\ldots$ & $2.2 / 2.6$ & -0.65 & $\ldots$ & 2,3 \\
\hline SL 397 & 0.42 & 0.7 & 0.081 & $0.16 \pm 0.03$ & -0.40 & $\ldots$ & $\ldots$ & $\mathrm{a}, \mathrm{b}$ & 4 \\
\hline H88-281 & 0.23 & 0.3 & 0.090 & $0.16 \pm 0.02$ & -0.40 & $\ldots$ & $\ldots$ & $\mathrm{b}$ & 8 \\
\hline H88-285 & 0.18 & 0.4 & 0.081 & $0.32 \pm 0.03$ & -0.40 & $\ldots$ & $\ldots$ & $\mathrm{m} 16 / \mathrm{b}$ & 8 \\
\hline SL 408A & 0.23 & 0.5 & 0.055 & $0.14 \pm 0.01$ & -0.40 & $\ldots$ & $\ldots$ & $\mathrm{a}, \mathrm{b}$ & 8 \\
\hline H88-286 & 0.14 & 0.4 & 0.081 & $0.32 \pm 0.03$ & -0.40 & $\ldots$ & $\ldots$ & $\mathrm{m} 16 / \mathrm{a}$ & 8 \\
\hline H88-287 & 0.23 & 0.4 & 0.081 & $0.16 \pm 0.02$ & -0.40 & $\ldots$ & $\ldots$ & $\mathrm{m} 16 / \mathrm{b}$ & 8 \\
\hline BSDL 1334 & 0.18 & 0.8 & 0.060 & $1.00 \pm 0.10$ & -0.40 & $\ldots$ & $\ldots$ & $\mathrm{b}, \mathrm{c}$ & 8 \\
\hline HS 247 & 0.33 & 0.6 & 0.127 & $0.35 \pm 0.07$ & -0.40 & $\ldots$ & $\ldots$ & $\mathrm{b}$ & 4 \\
\hline BSDL 1364 & 0.09 & 0.9 & 0.060 & $0.16 \pm 0.02$ & -0.40 & $\ldots$ & $\ldots$ & $\ldots$ & 8 \\
\hline HS 253 & 0.45 & 0.7 & 0.085 & $0.22_{-0.02}^{+0.03}$ & -0.36 & $\ldots$ & $\ldots$ & $\mathrm{b}, \mathrm{c}$ & 17 \\
\hline KMK88-52 & 0.45 & 0.6 & 0.085 & $0.18 \pm 0.02$ & +0.02 & $\ldots$ & $\ldots$ & $\mathrm{m} 17$ & 17 \\
\hline IC 2134 & 0.50 & 6.9 & 0.107 & $\ldots$ & $\ldots$ & 1.00 & $\ldots$ & $\ldots$ & 3 \\
\hline HS 264 & $\ldots$ & 1.5 & 0.083 & $\ldots$ & $\ldots$ & 1.60 & $\ldots$ & $\mathrm{a}$ & 1 \\
\hline SL 451 & $\ldots$ & 7.0 & 0.106 & $\ldots$ & $\ldots$ & 2.20 & -0.70 & $\ldots$ & 2,3 \\
\hline SL 446A & $\ldots$ & 2.0 & 0.060 & $2.20 \pm 0.50$ & -0.90 & $2.30 / 2.40$ & -0.75 & $\mathrm{a}$ & 2,12 \\
\hline SL 444 & $\ldots$ & 2.0 & 0.060 & $0.50 \pm 0.10$ & -0.40 & $\ldots$ & $\ldots$ & a & 11 \\
\hline LW 211 & 0.72 & 4.7 & 0.097 & $1.80_{-0.2}^{+0.4}$ & -0.67 & $\ldots$ & $\ldots$ & $\ldots$ & 5,17 \\
\hline SL 460 & 0.72 & 0.5 & 0.062 & $0.02_{-0.006}^{+0.012}$ & -0.47 & $\ldots$ & $\ldots$ & $\mathrm{m} 18 / \mathrm{c}$ & 17 \\
\hline SL 469 & 0.54 & 0.5 & 0.062 & $0.16 \pm 0.02$ & -0.44 & $\ldots$ & $\ldots$ & $\mathrm{c}$ & 17 \\
\hline КМНК 907 & 0.35 & 1.7 & 0.091 & $0.25 \pm 0.05$ & -0.40 & $\ldots$ & $\ldots$ & $\ldots$ & 4 \\
\hline BSDL 1723 & 0.45 & 0.5 & 0.062 & $0.28 \pm 0.03$ & -0.40 & $\ldots$ & $\ldots$ & c & 17 \\
\hline NGC 1969 & 0.63 & 0.5 & 0.062 & $0.16_{-0.03}^{+0.09}$ & -0.54 & $\ldots$ & $\ldots$ & $\mathrm{m} 19$ & 17 \\
\hline NGC 1971 & 0.50 & 0.5 & 0.062 & $0.14_{-0.3}^{+0.11}$ & -0.47 & $\ldots$ & $\ldots$ & $\mathrm{m} 19$ & 17 \\
\hline NGC 1972 & 0.36 & 0.5 & 0.062 & $0.16_{-0.03}^{+0.09}$ & -0.44 & $\ldots$ & $\ldots$ & m19 & 17 \\
\hline KMK88-57 & 0.41 & 0.6 & 0.062 & $0.80_{-0.24}^{+0.2}$ & -0.54 & $\ldots$ & $\ldots$ & $\mathrm{m} 20 / \mathrm{c}$ & 17 \\
\hline SL 490 & 0.99 & 4.8 & 0.120 & $2.20_{-0.40}^{+0.30}$ & -0.66 & 1.80 & -0.80 & $\ldots$ & 7,13 \\
\hline
\end{tabular}


Table A.2. continued.

\begin{tabular}{|c|c|c|c|c|c|c|c|c|c|}
\hline ID & $\begin{array}{l}\text { Radius } \\
\text { (arcmin) }\end{array}$ & $\begin{array}{c}\text { Deproj. } \\
\text { dist (deg) }\end{array}$ & $E(B-V)$ & $\begin{array}{l}\mathrm{Age}_{\mathrm{I}} \\
(\mathrm{Gyr})\end{array}$ & $\begin{array}{c}{[\mathrm{Fe} / \mathrm{H}]_{\mathrm{I}}} \\
(\mathrm{dex})\end{array}$ & $\begin{array}{c}\text { Age }_{\text {II }} \\
( \pm 0.30 \mathrm{Gyr})\end{array}$ & $\begin{array}{c}{[\mathrm{Fe} / \mathrm{H}]_{\mathrm{II}}} \\
( \pm 0.3 \mathrm{dex})\end{array}$ & Notes & Ref. \\
\hline SL 506 & 1.35 & 4.8 & 0.106 & $1.80 \pm 0.20$ & -0.66 & 1.70 & -0.80 & $\ldots$ & 17 \\
\hline SL 505 & $\ldots$ & 2.5 & 0.070 & $0.90 \pm 0.20$ & -0.50 & $1.60 / 1.50$ & -0.70 & $\mathrm{a}$ & 2,12 \\
\hline SL 510 & 0.17 & 1.4 & 0.080 & $0.13 \pm 0.03$ & -0.40 & $\ldots$ & $\ldots$ & $\mathrm{a}$ & 9 \\
\hline КМНК 979 & 0.33 & 1.8 & 0.086 & $0.08 \pm 0.02$ & -0.40 & $\ldots$ & $\ldots$ & $\mathrm{m} 21 \mathrm{a}$ & 4 \\
\hline HS 329 & 0.65 & 1.8 & 0.000 & $0.79-1.00 \pm 0.23$ & -0.40 & 1.80 & $\ldots$ & $\mathrm{m} 21$ & 1,6 \\
\hline SL 509 & $\ldots$ & 6.6 & 0.030 & $\ldots$ & $\ldots$ & $1.40 / 1.20$ & -0.85 & $\ldots$ & 2,3 \\
\hline LW 224 & $\ldots$ & 3.0 & 0.060 & $0.70 \pm 0.10$ & 0.00 & $\ldots$ & $\ldots$ & $\mathrm{m} 22$ & 11 \\
\hline KMHK 975 & 0.35 & 1.9 & 0.051 & $0.20 \pm 0.04$ & -0.40 & $\ldots$ & $\ldots$ & $\ldots$ & 4 \\
\hline LW 231 & 0.52 & 6.7 & 0.110 & $0.80_{-0.17}^{+0.20}$ & -0.50 & $\ldots$ & $\ldots$ & $\ldots$ & 7,13 \\
\hline NGC 1997 & 0.80 & 7.1 & 0.040 & $2.60 \pm 0.50$ & -0.70 & 2.70 & $\ldots$ & $\ldots$ & 6 \\
\hline КMHK 993 & 0.18 & 1.6 & 0.062 & $0.10 \pm 0.01$ & -0.40 & $\ldots$ & $\ldots$ & $\ldots$ & 8 \\
\hline SL 548 & $\ldots$ & 3.0 & 0.080 & $0.40 \pm 0.10$ & 0.00 & $\ldots$ & $\ldots$ & $\ldots$ & 11 \\
\hline SL 555 & $\ldots$ & 3.1 & 0.070 & $1.60 \pm 0.30$ & -0.70 & $1.60 / 1.80$ & -0.75 & $\mathrm{a}$ & 2,12 \\
\hline КМHK 1023 & $\ldots$ & 1.6 & 0.062 & $\ldots$ & $\ldots$ & 1.70 & $\ldots$ & $\ldots$ & 1 \\
\hline SL 551 & 0.33 & 1.8 & 0.091 & $0.14 \pm 0.03$ & -0.40 & $\ldots$ & $\ldots$ & $\mathrm{m} 23 / \mathrm{a}, \mathrm{b}$ & 4 \\
\hline KMHK 1029 & 0.27 & 2.0 & 0.058 & $0.10 \pm 0.01$ & -0.40 & $\ldots$ & $\ldots$ & $\mathrm{b}$ & 8 \\
\hline BRHT 38b & 0.50 & 1.9 & 0.081 & $0.18 \pm 0.04$ & -0.40 & $\ldots$ & $\ldots$ & $\mathrm{m} 23 / \mathrm{b}$ & 4 \\
\hline SL 549 & $\ldots$ & 5.9 & 0.040 & $2.00 \pm 0.50$ & -0.90 & $1.30 / 2.00$ & $\ldots$ & $\ldots$ & 2,12 \\
\hline КМНК 1045 & 0.17 & 1.9 & 0.060 & $0.60 \pm 0.10$ & -0.40 & $\ldots$ & $\ldots$ & $\mathrm{b}$ & 9 \\
\hline KMHK 1055 & 0.17 & 2.0 & 0.060 & $1.00 \pm 0.20$ & -0.40 & $\ldots$ & $\ldots$ & $a, b$ & 9 \\
\hline $\mathrm{H} 3$ & $\ldots$ & 1.8 & 0.062 & $\ldots$ & $\ldots$ & 2.50 & $\ldots$ & $\ldots$ & 1 \\
\hline IC 2140 & 1.17 & 6.8 & 0.111 & $2.50_{-0.5}^{+0.6}$ & -0.84 & 2.10 & -1.10 & $\ldots$ & 7 \\
\hline SL 579 & 0.30 & 2.1 & 0.066 & $0.14 \pm 0.03$ & -0.40 & $\ldots$ & $\ldots$ & $a, b$ & 4 \\
\hline SL 588 & 0.67 & 1.7 & 0.060 & $0.40 \pm 0.10$ & -0.40 & $\ldots$ & $\ldots$ & $\mathrm{b}$ & 9 \\
\hline IC 2146 & $\ldots$ & 6.1 & 0.117 & $\ldots$ & $\ldots$ & 1.60 & $\ldots$ & $\ldots$ & 1 \\
\hline LW 263 & $\ldots$ & 6.2 & 0.117 & $\ldots$ & $\ldots$ & 1.80 & $\ldots$ & $\ldots$ & 1 \\
\hline H88-306 & 0.14 & 1.8 & 0.063 & $0.13 \pm 0.01$ & -0.40 & $\ldots$ & $\ldots$ & $\mathrm{m} 24$ & 8 \\
\hline H88-313 & 0.18 & 1.9 & 0.064 & $0.13 \pm 0.01$ & -0.40 & $\ldots$ & $\ldots$ & $\mathrm{b}$ & 8 \\
\hline HS 390 & 0.33 & 1.9 & 0.228 & $0.18 \pm 0.04$ & -0.40 & $\ldots$ & $\ldots$ & $\mathrm{b}$ & 4 \\
\hline H88-315 & 0.18 & 2.0 & 0.063 & $0.08 \pm 0.01$ & -0.40 & $\ldots$ & $\ldots$ & $a, b$ & 8 \\
\hline NGC 2093 & 0.50 & 2.0 & 0.070 & $0.25 \pm 0.05$ & -0.40 & $\ldots$ & $\ldots$ & $\mathrm{m} 25 / \mathrm{a}, \mathrm{b}$ & 9 \\
\hline H88-320 & 0.45 & 2.0 & 0.168 & $0.16 \pm 0.03$ & -0.40 & $\ldots$ & $\ldots$ & $\mathrm{a}, \mathrm{b}$ & 4 \\
\hline H88-321 & 0.18 & 2.0 & 0.063 & $0.08 \pm 0.01$ & -0.40 & $\ldots$ & $\ldots$ & $\mathrm{b}$ & 8 \\
\hline SL 663 & 1.93 & 4.8 & 0.040 & $2.80 \pm 0.35$ & -0.70 & 3.30 & $\ldots$ & $\ldots$ & 6 \\
\hline H88-325 & 0.18 & 2.1 & 0.072 & $0.22 \pm 0.02$ & -0.40 & $\ldots$ & $\ldots$ & $\ldots$ & 8 \\
\hline SL 674 & $\ldots$ & 3.9 & 0.050 & $2.00 \pm 0.40$ & -0.90 & $2.10 / 2.30$ & -0.80 & $\mathrm{a}$ & 2,12 \\
\hline H88-326 & 0.18 & 2.1 & 0.072 & $0.32 \pm 0.03$ & -0.40 & $\ldots$ & $\ldots$ & $a, b$ & 8 \\
\hline SL 678 & $\ldots$ & 4.0 & 0.050 & $1.50 \pm 0.30$ & -0.80 & 2.00 & -0.80 & $\mathrm{a}$ & 12 \\
\hline H88-327 & 0.27 & 2.1 & 0.074 & $0.03 \pm 0.00$ & -0.40 & $\ldots$ & $\ldots$ & $\mathrm{m} 26$ & 8 \\
\hline H88-329 & 0.18 & 2.2 & 0.072 & $0.06 \pm 0.01$ & -0.40 & $\ldots$ & $\ldots$ & $\mathrm{b}$ & 8 \\
\hline NGC 2108 & $\ldots$ & 2.2 & 0.072 & $\ldots$ & $\ldots$ & 1.25 & $\ldots$ & $\ldots$ & 1 \\
\hline H88-331 & 0.40 & 2.2 & 0.117 & $0.50 \pm 0.10$ & -0.40 & $\ldots$ & $\ldots$ & $\ldots$ & 4 \\
\hline SL 691 & 0.38 & 2.3 & 0.068 & $0.28_{-0.08}^{+0.07}$ & -0.47 & $\ldots$ & $\ldots$ & $\mathrm{m} 27 / \mathrm{a}, \mathrm{c}$ & 17 \\
\hline SL 692 & 0.47 & 2.3 & 0.068 & $0.25 \pm 0.03$ & -0.41 & $\ldots$ & $\ldots$ & $\mathrm{m} 27 / \mathrm{a}, \mathrm{c}$ & 17 \\
\hline BSDL 2938 & 0.45 & 2.3 & 0.067 & $0.45_{-0.10}^{+0.18}$ & -0.23 & $\ldots$ & $\ldots$ & $\ldots$ & 17 \\
\hline HS 406 & 0.32 & 2.3 & 0.067 & $0.32_{-0.04}^{+0.03}$ & -0.23 & $\ldots$ & $\ldots$ & $\mathrm{c}$ & 17 \\
\hline HS 409 & 0.50 & 2.3 & 0.067 & $0.45_{-0.13}^{+0.11}$ & -0.27 & $\ldots$ & $\ldots$ & $\mathrm{c}$ & 7 \\
\hline BSDL 2950 & 0.27 & 2.3 & 0.067 & $0.71 \pm 0.08$ & -0.36 & $\ldots$ & $\ldots$ & $\mathrm{c}$ & 17 \\
\hline BSDL 2963 & 0.52 & 2.4 & 0.068 & $1.25_{-0.1}^{+0.2}$ & 0.00 & $\ldots$ & $\ldots$ & $\mathrm{c}$ & 17 \\
\hline SL 704 & 0.45 & 2.3 & 0.067 & $0.45_{-0.05}^{+0.11}$ & -0.16 & $\ldots$ & $\ldots$ & $\mathrm{c}$ & 17 \\
\hline H88-333 & 0.33 & 2.3 & 0.070 & $0.40 \pm 0.10$ & -0.40 & $\ldots$ & $\ldots$ & $\ldots$ & 9 \\
\hline HS 410 & 0.63 & 2.5 & 0.068 & $0.56 \pm 0.06$ & -0.27 & $\ldots$ & $\ldots$ & $\mathrm{c}$ & 17 \\
\hline BSDL 2972 & 0.43 & 2.5 & 0.068 & $0.71_{-0.1}^{+0.09}$ & 0.00 & $\ldots$ & $\ldots$ & $\mathrm{c}$ & 17 \\
\hline HS 411 & 0.25 & 2.4 & 0.173 & $0.28 \pm 0.06$ & -0.40 & $\ldots$ & $\ldots$ & $\ldots$ & 4 \\
\hline HS 412 & 0.42 & 2.4 & 0.173 & $0.13 \pm 0.03$ & -0.40 & $\ldots$ & $\ldots$ & $\mathrm{a}$ & 4 \\
\hline
\end{tabular}


T. Palma et al.: Catalogue of LMC star clusters observed in the Washington system.

Table A.2. continued.

\begin{tabular}{|c|c|c|c|c|c|c|c|c|c|}
\hline ID & $\begin{array}{l}\text { Radius } \\
\text { (arcmin) }\end{array}$ & $\begin{array}{c}\text { Deproj. } \\
\text { dist (deg) }\end{array}$ & $E(B-V)$ & $\begin{array}{l}\mathrm{Age}_{\mathrm{I}} \\
(\mathrm{Gyr})\end{array}$ & $\begin{array}{c}{[\mathrm{Fe} / \mathrm{H}]_{\mathrm{I}}} \\
(\mathrm{dex})\end{array}$ & $\begin{array}{c}\text { Age }_{\text {II }} \\
( \pm 0.30 \mathrm{Gyr})\end{array}$ & $\begin{array}{c}{[\mathrm{Fe} / \mathrm{H}]_{\mathrm{II}}} \\
( \pm 0.3 \mathrm{dex})\end{array}$ & Notes & Ref. \\
\hline BSDL 2978 & 0.27 & 2.5 & 0.068 & $0.90_{-0.27}^{+0.2}$ & -0.23 & $\ldots$ & $\ldots$ & $\mathrm{c}$ & 17 \\
\hline LOGLE 733 & 0.27 & 2.5 & 0.068 & $0.80_{-0.24}^{+0.2}$ & -0.10 & $\ldots$ & $\ldots$ & $\mathrm{c}$ & 17 \\
\hline SL 707 & $\ldots$ & 2.4 & 0.072 & $\ldots$ & $\ldots$ & 2.30 & $\ldots$ & $\ldots$ & 1 \\
\hline BSDL 2993 & 0.59 & 2.5 & 0.068 & $0.71 \pm 0.08$ & -0.36 & $\ldots$ & $\ldots$ & $\mathrm{c}$ & 17 \\
\hline HS 414 & 0.45 & 2.6 & 0.086 & $0.32_{-0.04}^{+0.03}$ & -0.31 & $\ldots$ & $\ldots$ & $\mathrm{m} 28 / \mathrm{a}, \mathrm{c}$ & 17 \\
\hline SL 716 & 0.20 & 2.6 & 0.068 & $0.28_{-0.03}^{+0.04}$ & -0.10 & $\ldots$ & $\ldots$ & $\mathrm{m} 28 / \mathrm{a}, \mathrm{c}$ & 17 \\
\hline BSDL 3001 & 0.77 & 2.5 & 0.068 & $0.28_{-0.03}^{+0.04}$ & -0.31 & $\ldots$ & $\ldots$ & $\mathrm{a}, \mathrm{c}$ & 17 \\
\hline BSDL 2995 & 0.50 & 2.4 & 0.070 & $1.00 \pm 0.20$ & -0.40 & $\ldots$ & $\ldots$ & $\mathrm{m} 29$ & 9 \\
\hline BSDL 3000 & 0.63 & 2.5 & 0.067 & $0.22_{-0.03}^{+0.02}$ & 0.00 & $\ldots$ & $\ldots$ & $\mathrm{c}$ & 17 \\
\hline BSDL 3003 & 0.41 & 2.6 & 0.068 & $0.45 \pm 0.05$ & -0.31 & $\ldots$ & $\ldots$ & $\mathrm{c}$ & 17 \\
\hline H88-334 & $\ldots$ & 2.5 & 0.072 & $\ldots$ & $\ldots$ & 2.00 & $\ldots$ & $\ldots$ & 1 \\
\hline BSDL 3050 & 0.34 & 2.5 & 0.067 & $0.28_{-0.03}^{+0.04}$ & -0.31 & $\ldots$ & $\ldots$ & $\mathrm{m} 30$ & 17 \\
\hline КМHK 1389 & 0.36 & 2.6 & 0.067 & $0.16 \pm 0.02$ & -0.31 & $\ldots$ & $\ldots$ & $\mathrm{m} 30$ & 17 \\
\hline BSDL 3060 & 0.50 & 2.6 & 0.067 & $0.45_{-0.1}^{+0.11}$ & -0.47 & $\ldots$ & $\ldots$ & $\ldots$ & 7 \\
\hline HS 420 & 0.41 & 2.6 & 0.073 & $0.32_{-0.07}^{+0.08}$ & -0.27 & $\ldots$ & $\ldots$ & $\ldots$ & 7 \\
\hline BSDL 3072 & 0.41 & 2.6 & 0.073 & $0.40_{-0.08}^{+0.01}$ & -0.31 & $\ldots$ & $\ldots$ & $\mathrm{m} 30$ & 7 \\
\hline BSDL 3071 & 0.27 & 2.5 & 0.075 & $0.14 \pm 0.20$ & -0.41 & $\ldots$ & $\ldots$ & $\ldots$ & 17 \\
\hline КMHK 1408 & 0.59 & 2.6 & 0.073 & $0.50_{-0.1}^{+0.13}$ & -0.33 & $\ldots$ & $\ldots$ & $\mathrm{m} 30$ & 7 \\
\hline SL 736 & 0.90 & 2.7 & 0.070 & $0.40_{-0.08}^{+0.10}$ & -0.19 & $\ldots$ & $\ldots$ & $\ldots$ & 7 \\
\hline HS 424 & 0.50 & 2.7 & 0.074 & $0.40_{-0.08}^{+0.11}$ & -0.23 & $\ldots$ & $\ldots$ & $\ldots$ & 7 \\
\hline $\mathrm{H} 7$ & & 3.2 & 0.065 & & $\ldots$ & 1.40 & $\ldots$ & $\ldots$ & 2 \\
\hline SL 748 & 0.90 & 2.7 & 0.073 & $0.25_{-0.04}^{+0.07}$ & -0.36 & $\ldots$ & $\ldots$ & $\mathrm{m} 31 / \mathrm{a}$ & 17 \\
\hline HS 427 & 0.86 & 2.8 & 0.074 & $0.32 \pm 0.03$ & -0.36 & $\ldots$ & $\ldots$ & $\ldots$ & 17 \\
\hline КMHK 1448 & 0.54 & 2.8 & 0.073 & $0.28_{-0.03}^{+0.04}$ & -0.31 & $\ldots$ & $\ldots$ & $\ldots$ & 17 \\
\hline BSDL 3123 & 0.32 & 2.8 & 0.073 & $0.40_{-0.08}^{+0.10}$ & -0.31 & $\ldots$ & $\ldots$ & $\ldots$ & 7 \\
\hline $\mathrm{C} 11$ & 0.68 & 3.4 & 0.101 & $0.40 \pm 0.05$ & -0.31 & $\ldots$ & $\ldots$ & $\ldots$ & 5 \\
\hline BSDL 3158 & 0.99 & 3.5 & 0.101 & $2.50 \pm 0.30$ & -0.40 & 2.10 & -0.80 & $\ldots$ & 5,17 \\
\hline КМHK 1504 & 0.63 & 3.6 & 0.117 & $2.20_{-0.40}^{+0.30}$ & -0.72 & $\ldots$ & -0.80 & $\ldots$ & 7 \\
\hline SL 769 & $\ldots$ & $\ldots$ & 0.076 & $\ldots$ & $\ldots$ & 1.80 & -0.50 & $\ldots$ & 3 \\
\hline H88-365 & 0.41 & 3.5 & 0.101 & $0.28 \pm 0.06$ & -0.40 & $\ldots$ & $\ldots$ & $\mathrm{a}$ & 13,17 \\
\hline SL 775 & 0.95 & 3.5 & 0.090 & $0.63_{-0.13}^{+0.17}$ & -0.50 & $\ldots$ & $\ldots$ & $\ldots$ & 7 \\
\hline OHSC 28 & 0.33 & 8.3 & 0.040 & $2.20 \pm 0.25$ & -0.70 & 2.70 & $\ldots$ & $\ldots$ & 6 \\
\hline NGC 2161 & 1.50 & 5.9 & 0.130 & $1.10 \pm 0.30$ & -0.70 & $\ldots$ & $\ldots$ & $\ldots$ & 14 \\
\hline NGC 2153 & $\ldots$ & 4.6 & 0.035 & $\ldots$ & $\ldots$ & 1.30 & $\ldots$ & $\mathrm{a}$ & 2 \\
\hline NGC 2155 & $\ldots$ & 5.4 & 0.050 & $3.20 \pm 0.60$ & -0.90 & 3.60 & $\ldots$ & $\ldots$ & 15 \\
\hline SL 817 & $\ldots$ & 3.6 & 0.070 & $\ldots$ & $\ldots$ & $2.5 / 1.5$ & -0.50 & $\ldots$ & 2,3 \\
\hline SL 826 & 1.17 & 4.4 & 0.112 & $2.50_{-0.30}^{+0.70}$. & -0.78 & 2.10 & -0.90 & $\ldots$ & 17 \\
\hline ESO 121-03 & $\ldots$ & 10.4 & 0.030 & $\ldots$ & $\ldots$ & 8.50 & -1.05 & $\ldots$ & 2,3 \\
\hline LW 393 & $\ldots$ & 4.6 & 0.116 & $\ldots$ & $\ldots$ & 1.80 & $\ldots$ & $\ldots$ & 1 \\
\hline LW 397 & $\ldots$ & 4.9 & 0.109 & $\ldots$ & $\ldots$ & 1.80 & $\ldots$ & $\ldots$ & 1 \\
\hline SL 842 & 0.40 & 8.1 & 0.030 & $\ldots$ & $\ldots$ & $1.90 / 2.20$ & -0.60 & $\ldots$ & 2,3 \\
\hline KMHK 1668 & $\ldots$ & 4.9 & 0.109 & $\ldots$ & $\ldots$ & 1.70 & $\ldots$ & $\ldots$ & 1 \\
\hline NGC 2213 & $\ldots$ & 4.6 & 0.116 & 1.5 & -0.40 & $\ldots$ & $\ldots$ & $\ldots$ & 16 \\
\hline SL 862 & $\ldots$ & 4.7 & 0.090 & $\ldots$ & $\ldots$ & 1.80 & -0.85 & $\ldots$ & 2,3 \\
\hline SL 870 & 1.04 & 5.4 & 0.088 & $1.25_{-0.1}^{+0.2}$ & -0.40 & 1.20 & $\ldots$ & $\ldots$ & 5,17 \\
\hline SL 869 & $\ldots$ & 4.9 & 0.101 & $\ldots$ & $\ldots$ & 1.70 & $\ldots$ & $\ldots$ & 1 \\
\hline KMHK 1702 & 0.45 & 5.3 & 0.110 & $1.12 \pm 0.10$ & -0.72 & 1.20 & $\ldots$ & $\ldots$ & 5,17 \\
\hline OHSC 33 & $\ldots$ & 6.2 & 0.090 & $\ldots$ & $\ldots$ & $1.20 / 1.40$ & -1.00 & $\mathrm{~m} 32 / \mathrm{c}$ & 2,3 \\
\hline SL 874 & 0.84 & 4.9 & 0.090 & $1.50 \pm 0.30$ & -0.70 & $\ldots$ & $\ldots$ & $\ldots$ & 14 \\
\hline КМНК 1719 & 0.42 & 5.1 & 0.090 & $1.40 \pm 0.30$ & -0.60 & $\ldots$ & $\ldots$ & $\ldots$ & 14 \\
\hline LW 469 & 0.50 & 5.9 & 0.080 & $0.60 \pm 0.10$ & -0.40 & $\ldots$ & $\ldots$ & $\ldots$ & 9 \\
\hline SL 896 & $\ldots$ & 6.4 & 0.070 & $2.30 \pm 0.30$ & -0.60 & 2.30 & $\ldots$ & $\ldots$ & 15 \\
\hline OHSC 37 & $\ldots$ & 9.4 & 0.150 & $\ldots$ & $\ldots$ & $2.70 / 2.10$ & -0.65 & $\ldots$ & 2,3 \\
\hline
\end{tabular}

